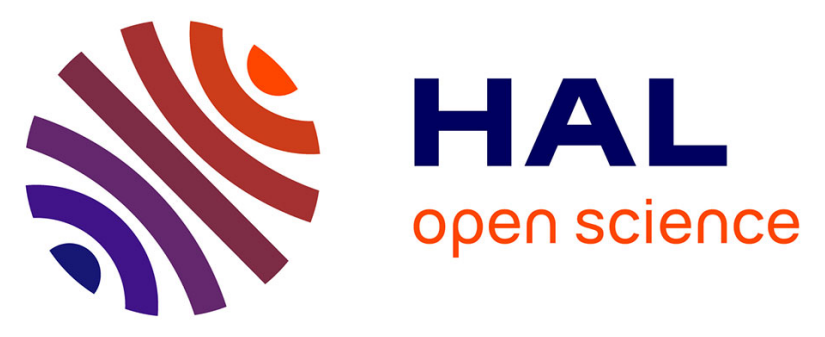

\title{
Impact of the unfolded protein response upon genome-wide expression patterns, and the role of Hac1 in the polarized growth, of Candida albicans
}

Tithira T Wimalasena, Brice Enjalbert, Thomas Guillemette, Andrew

Plumridge, Susan Budge, Z. Yin, Alistair J.P. Brown, David B Archer

\section{To cite this version:}

Tithira T Wimalasena, Brice Enjalbert, Thomas Guillemette, Andrew Plumridge, Susan Budge, et al.. Impact of the unfolded protein response upon genome-wide expression patterns, and the role of Hac1 in the polarized growth, of Candida albicans. Fungal Genetics and Biology, 2008, 45 (9), pp.1235-1247. 10.1016/j.fgb.2008.06.001 . hal-02146795

\section{HAL Id: hal-02146795 \\ https://hal.science/hal-02146795}

Submitted on 7 Jun 2019

HAL is a multi-disciplinary open access archive for the deposit and dissemination of scientific research documents, whether they are published or not. The documents may come from teaching and research institutions in France or abroad, or from public or private research centers.
L'archive ouverte pluridisciplinaire HAL, est destinée au dépôt et à la diffusion de documents scientifiques de niveau recherche, publiés ou non, émanant des établissements d'enseignement et de recherche français ou étrangers, des laboratoires publics ou privés. 


\title{
Impact of the unfolded protein response upon genome-wide expression patterns, and the role of Hac1 in the polarized growth, of Candida albicans
}

\author{
Tithira T. Wimalasena ${ }^{a}$, Brice Enjalbert ${ }^{\mathrm{b}, 1}$, Thomas Guillemette ${ }^{\mathrm{a}, 2}$, Andrew Plumridge ${ }^{\mathrm{a}, 3}$, Susan Budge ${ }^{\mathrm{b}}$, \\ Z. Yin ${ }^{\mathrm{b}}$, Alistair J.P. Brown ${ }^{\mathrm{b}}$, David B. Archer ${ }^{\mathrm{a}, *}$ \\ ${ }^{a}$ School of Biology, University of Nottingham, University Park, Nottingham NG7 2RD, UK \\ ${ }^{\mathrm{b}}$ Aberdeen Fungal Group, School of Medical Sciences, University of Aberdeen, Institute of Medical Sciences, Foresterhill, Aberdeen AB25 2ZD, UK
}

\section{Keywords:}

HAC1

Pseudohyphae

UPR

Candida albicans

UPR

ER stress

\begin{abstract}
A B S T R A C T
The unfolded protein response (UPR) regulates the expression of genes involved in the protein secretory pathway and in endoplasmic reticulum (ER) stress in yeasts and filamentous fungi. We have characterized the global transcriptional response of Candida albicans to ER stresses (dithiothreitol and tunicamycin) and established the impact of the transcription factor Hac1 upon this response. Expression of C. albicans Hac1, which is the functional homologue of Saccharomyces cerevisiae Hac1p, is predicted to be translationally regulated via an atypical mRNA splicing event during ER stress. $C$. albicans genes involved in secretion, vesicle trafficking, stress responses and cell wall biogenesis are up-regulated in response to ER stress, and translation and ribosome biogenesis genes are down-regulated. Hac1 is not essential for $C$. albicans viability, but plays a major role in this stress-related transcriptional response and is required for resistance to ER stress. In addition, we show that Hac1 plays an important role in regulating the morphology of $C$. albicans and in the expression of genes encoding cell surface proteins during ER stress, factors that are important in virulence of this fungal pathogen.
\end{abstract}

\section{Introduction}

Candida albicans is a commensal organism in humans that, under some circumstances, causes diseases which range from mucosal colonisation of otherwise healthy people (oral thrush and vaginitis) to invasive infections of people with impaired immune systems (Calderone, 2002). The ability of $C$. albicans to colonize diverse tissues and artificial surfaces such as catheters suggests a phenotypic versatility in its cell surface properties (reviewed by Verstrepen et al., 2004; Verstrepen and Klis, 2006) as well the existence of robust adaptive environmental responses.

Candida albicans can grow as budding yeast, in a pseudohyphal form or as true hyphae depending upon the environmental conditions (Sudbery et al., 2004). Growth is polarized in C. albicans hyphae, with continuous apical growth throughout the cell cycle and parallel cell walls at the septal junctions. In contrast, the growth of pseudohyphae and blastophores is only limited to the

\footnotetext{
* Corresponding author. Fax: +44 1159513251.

E-mail address: david.archer@nottingham.ac.uk (D.B. Archer).

1 Present address: UMR5504, LISBP/INSA, 135 Avenue de Rangueil, 31077 Toulouse cedex 4, France.

2 Present address: Laboratoire de Microbiologie, Université d'Angers, 2 bd. Lavoisier, 49045 Angers cedex, France.

3 Present address: Novozymes Biopharma UK Ltd., 59 Castle Boulevard, Nottingham NG71FD, UK.
}

apical tip during the initial part of the cell cycle (Court and Sudbery, 2007). C. albicans pseudohyphae have a constriction at the septal junction between mother and daughter cells. Pseudohyphae can be distinguished from true hyphae on the basis of their morphological index (Mi) which quantifies the dimensions of cell compartments (Merson-Davis and Odds, 1989). Alternatively they can be distinguished on the basis of the positions of their septal junctions. These lie at the bud neck for pseudohyphae, and within the germ tube for an emerging hypha (Sudbery et al., 2004).

The yeast-hyphal transition is regulated by a complex network of signalling pathways that include evolutionarily conserved MAP kinase and Ras-cAMP modules (reviewed by Ernst, 2000; Gow et al., 2002; Sudbery et al., 2004; Whiteway and Oberholzer, 2004; Brown et al., 2007). The yeast-like form is thought to promote dissemination within the blood stream whereas hyphal development appears to promote invasion (Gow et al., 2002; Sundström, 2006). The link between specific morphotypes and virulence is not firmly established (Gow et al., 2002). However, hyphae are important for the formation of biofilms, which can provide reservoirs of infection in the host, and morphogenetic variation is likely to be important in responding rapidly to environmental change and to host defence mechanisms (Odds, 1988).

Generally, growth of $C$. albicans in the yeast form is favoured at high cell densities, temperatures below $30^{\circ} \mathrm{C}$, and ambient $\mathrm{pH}$ below 4 . In contrast, the hyphal form is favoured at temperatures 
above $37^{\circ} \mathrm{C}$, at ambient pH close to 7 , at lower cell densities, at high $\mathrm{CO}_{2}$ concentrations, under some limiting nutrient conditions such as amino acid starvation or hypoxia, or in the presence of serum (Odds, 1988; Tripathi et al., 2002; Enjalbert and Whiteway, 2005; Klengel et al., 2005). The effect of serum is complex but it is proposed to act, in part, by conferring amino acid starvation (Tripathi et al., 2002) although other factors are implicated (Maidan et al., 2005; Hudson et al., 2004).

The mechanisms of fungal protein secretion are similar to those in other eukaryotes (Schröder and Kaufman, 2005a,b). The assisted folding of proteins within the lumen of the endoplasmic reticulum (ER) represents a critical step in the secretory pathway because, at this stage, improperly folded proteins are detected and degraded. A build-up of unfolded proteins induces the unfolded protein response (UPR) in the model yeast Saccharomyces cerevisiae. This response is triggered by the ER trans-membrane sensor and endonuclease Ire1p, which leads to activation of the transcript encoding the bZIP transcription factor Hac1p (sometimes referred to as Hac1 $p^{\mathrm{i}}$ where ' $\mathrm{i}$ ' means induced). Hac1p synthesis is dependent on the splicing of an atypical (non-spliceosomal) intron in the HAC1 mRNA in all organisms examined to date. The HAC1 intron is 252 bp in S. cerevisiae (Cox and Walter, 1996; Mori et al., 1996) but about 20 bp long in filamentous fungi (Mulder et al., 2004; Saloheimo et al., 2003). This splicing event is activated in response to ER stress leading to the synthesis of functional Hac1p.

The Hac1 protein binds to specific motifs (unfolded protein response elements, UPREs) in responsive promoters to induce the transcription of $S$. cerevisiae genes encoding a variety of ER-resident chaperones and foldases, components of the protein secretory pathway, and genes involved in the ER-associated degradation (ERAD) of improperly-folded proteins. Travers et al. (2000) showed that nearly $400 \mathrm{~S}$. cerevisiae genes are induced following exposure to dithiothreitol (DTT) and tunicamycin, which are chemical inducers of the UPR. DTT is thought to induce the UPR by affecting the redox status of the ER lumen, which is important for the formation of disulphide bonds. Tunicamycin is an inhibitor of N-linked glycosylation of secretory proteins. Therefore, while DTT and tunicamycin both induce the UPR, they do not affect the transcription of identical sets of genes (Travers et al., 2000). The UPR has a profound impact upon $S$. cerevisiae, affecting the expression of genes involved in the protein folding, cell surface architecture and secretion (Travers et al., 2000; Kimata et al., 2005).

The roles of the UPR in S. cerevisiae have been extended with the realization that the UPR is a key sensor and mediator of nitrogenregulated effects. Activation of the HAC1 mRNA by splicing occurs only under nitrogen-sufficient conditions, and down-regulation of the UPR by nitrogen starvation leads to pseudohyphal growth in S. cerevisiae (Schröder et al., 2000). The transcriptional activation of UPR-sensitive genes involves both Hac1p and Gcn4p, two nitrogen-sensitive bZIP transcription factors (Patil et al., 2004). Further complexity in UPR regulation is also apparent (Leber et al., 2004; Schröder et al., 2003), indicating that this response is a versatile and sensitive regulatory mechanism involved in environmental adaptation and cellular development (Kaufman et al., 2002).

The extent of the UPR has not been explored in C. albicans. We reasoned that the UPR might be involved in the regulation of polarized growth in this pathogen for two main reasons. Firstly, the UPR is likely to influence the delivery of newly synthesized proteins to the apical tip, which is essential for polarized growth. Secondly, there is interconnection between the Hac1p and Gcn $4 p$ regulons in S. cerevisiae (Patil et al., 2004), and Gcn4p has been implicated in the regulation of filamentous growth in C. albicans (Tripathi et al., 2002; Tournu et al., 2005). Therefore, we have defined the genome-wide transcriptional response of $C$. albicans during the UPR, and confirmed that Hac1 plays an important role in hyphal development.

\section{Materials and methods}

\subsection{C. albicans strains, plasmids and growth conditions}

The C. albicans and S. cerevisiae strains used in this study are described in Table 1. Strains were grown in YPD containing $80 \mu \mathrm{g}$ uridine/ml, or synthetic complete (SC) medium (Sherman, 1991). For low nitrogen culturing conditions, we used SD medium without $\left(\mathrm{NH}_{4}\right)_{2} \mathrm{SO}_{4}$ and amino acids (Formedium), supplemented with $2 \%$ (w/v) glucose (Sherman, 1991). Morphogenesis was stimulated by transferring $C$. albicans yeast cells into RPMI-1640 (containing $25 \mathrm{mM}$ HEPES and $\mathrm{NaHCO}_{3}$ without L-glutamine) (Sigma) or by adding 20\% (v/v) foetal calf serum (Invitrogen) to yeast-like cells growing in YPD or SC at $37^{\circ} \mathrm{C}$ (Swoboda et al., 1994). The impact of amino acid starvation on the UPR was tested using the histidine analogue, 3-aminotriazole (3AT), which imposes histidine starvation in C. albicans (Tripathi et al., 2002; Tournu et al., 2005). Cells were grown in SC medium lacking histidine, with $30 \mathrm{mM} 3 \mathrm{AT}$ at $37^{\circ} \mathrm{C}$ for $4 \mathrm{~h}$. To stimulate the UPR in C. albicans, stationary phase cells were grown to mid-exponential phase $\left(\mathrm{OD}_{600}=0.5\right)$ in YPD at $30^{\circ} \mathrm{C}$ with shaking $(180 \mathrm{rpm})$, prior to the addition of $5 \mathrm{mM}$ dithiothreitol (DTT) or $4.73 \mu \mathrm{M}(4 \mu \mathrm{g} / \mathrm{ml})$ tunicamycin for $1 \mathrm{~h}$. Control cultures were treated with the equivalent volumes of carrier (distilled water and DMSO, respectively).

\subsection{Identification and analysis of $C$. albicans HAC1 sequences}

The C. albicans HAC1 locus was identified by interrogating the C. albicans genome (http://genolist.pasteur.fr/CandidaDB) with

Table 1

C. albicans and S. cerevisiae strains used in this study

\begin{tabular}{|c|c|c|}
\hline Strain & Genotype & Reference \\
\hline \multicolumn{3}{|l|}{ C. albicans strains } \\
\hline SC5314 & Prototrophic, clinical isolate & Gillum et al. (1984) \\
\hline BWP17 & 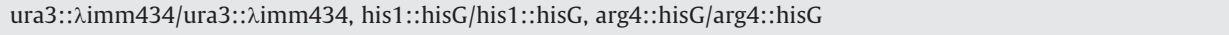 & Wilson et al. (1999) \\
\hline TW01 & 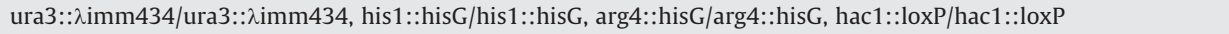 & This study \\
\hline TW02 (WT) & 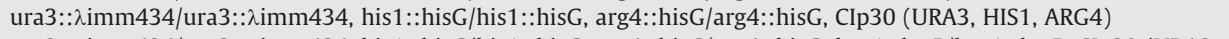 & This study \\
\hline TW03 (hac1/hac1) & 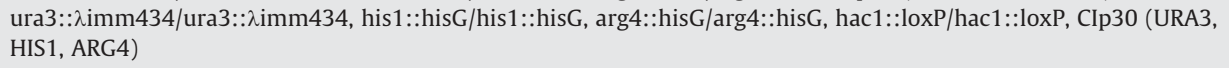 & This study \\
\hline $\begin{array}{l}\text { TW04 (hac1/hac1/ } \\
\text { HAC1) }\end{array}$ & 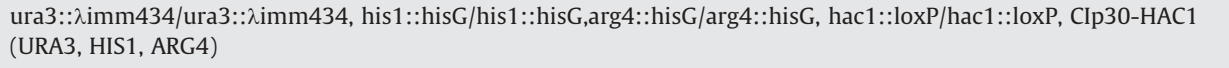 & This study \\
\hline \multicolumn{3}{|l|}{ S. cerevisiae strains } \\
\hline BY4741 & MATa his $3 \Delta 1$ leu $2 \Delta 0$ met $15 \Delta 0$ ura $3 \Delta 0$ & Euroscarf \\
\hline BY4741-hac1 & MATa his $3 \Delta 1$ leu $2 \Delta 0$ met $15 \Delta 0$ ura $3 \Delta 0$ hac $1 \Delta 0$ & Euroscarf \\
\hline BY4741-Hac1VTUTW01 & MATa his3 $\Delta 1$ leu2 $\Delta 0$ met15 $\Delta 0$ ura3 $\Delta 0$ hac1 $\Delta 0+$ pVTUTW01 & This study \\
\hline BY4741-Hac1VTUTW02 & MATa his3 $\Delta$ 1leu2 $\Delta$ 0met15 $\Delta 0$ ura3 $\Delta 0$ hac1 $\Delta 0+$ pVTUTW02 & This study \\
\hline
\end{tabular}


S. cerevisiae HAC1 (YFL031W, http://db.yeastgenome.org) using Blastn. Putative DNA-binding domains in the C. albicans HAC1 ORF were identified by Pfam searches http://pfam.wustl.edu/textsearch.shtml. Multiple-sequence alignments were constructed by using CLUSTAL W 1.6. RNA secondary structure prediction was performed with software from http://www.bioinfo.rpi.edu/applications/mfold/old/rna/.

To confirm the atypical intron in the HAC1 transcript, total RNA was extracted from C. albicans cells exposed to DTT or tunicamycin stress using Trizol (Invitrogen) (Hauser et al., 1998). Reverse transcription-polymerase chain reaction (RT-PCR) was performed on these RNA preparations using SuperScript III (Invitrogen) using the primers Hac1IF (5'-TGAGGATGAACACCAAGAAGAA) and Hac1IR (5'-TCAAAGTCCAACTG AAATGAT). The PCR products were cloned into pGEM $^{\circledR}$-T Easy (Promega) and sequenced on both strands (Sambrook et al., 1989).

To test for the presence of spliced and unspliced HAC1 transcripts, total RNA was isolated from test $C$. albicans cells (Hauser et al., 1998) and RT-PCR performed using primers that lie either side of the 19 bp intron: HAC1SPF (5'-AGACGCTTTTAATTACCACAC CA) and HAC1IR (5'-TCAAAGTCCAACTGAAATG). PCR amplification parameters were as follows: $95^{\circ} \mathrm{C}$ for $5 \mathrm{~min}$; 30 cycles consisting of $30 \mathrm{~s}$ at $95{ }^{\circ} \mathrm{C}, 30 \mathrm{~s}$ at $55^{\circ} \mathrm{C}$, and $30 \mathrm{~s}$ at $72{ }^{\circ} \mathrm{C}$; and $10 \mathrm{~min}$ at $72{ }^{\circ} \mathrm{C}$. The intron-containing $A C T 1$ sequence was used as a loading control and to test for genomic DNA contamination.

For RACE-PCR experiments, total RNA prepared from C. albicans cells was reverse-transcribed using SuperScript III and oligo-dT (20) primer (Invitrogen), and the Marathon cDNA Amplification Kit used following the manufacturer's instructions (Clontech). Amplification of cDNAs corresponding to HAC1 mRNA 3'-ends was performed using the Marathon cDNA amplification kit with the PCR anchor primer ( $3^{\prime} \mathrm{RACE} / \mathrm{AP} 1$ : Clontech) and the HAC1-specific primer, 5'-TGAGGATGAACACCAAGAAGAAGGTCA. Amplification of cDNA corresponding to HAC1 mRNA 5'-ends was performed using the HAC1-specific primer $5^{\prime}$-TGACTTCTTCTTGGGT TCACCTA with 5'RACE/AP1 (Clontech) for the first round of PCR. The second rounds of PCR were performed using the primer pairs 5'RACE/AP2 with 5'-TGGCTCTTTTCCTAGGTGGCAAAGTT (5'-HAC1specific), and 3'RACE/AP2 with 5'-AGACGCTTTTTGGAATTACCCATC ACCA (3'-HAC1-specific) for the $5^{\prime}$ and end 3' RACE analyses, respectively. The PCR products were cloned into PGEM $^{\circledR}-\mathrm{T}$ Easy and sequenced.

\subsection{Strain construction}

The hac1/hac1 null mutant was created using C. albicans BWP17 (Table 1) using the cre-loxP system described previously (Dennison et al., 2005). Briefly, hac1::loxP-ARG4-loxP (hac1::LAL) and hac1::loxP-HIS1-loxP (hac1::LHL) disruption cassettes containing about $120 \mathrm{bp}$ of sequence homology to the $5^{\prime}$ and $3^{\prime}$ ends of the HAC1 open reading frame (ORF), were generated by PCR using the primers HACdelF (5'-ATGGAGTTAACTGTTGATAACACCAATAC TACTTCCAATATAGATGATTTATCTGTTGCTACACCAACTTCTTTAATGA CAAGTACTACTACATCACCATCAATGTCAACATCAACAAGTCCAGGGTT TTCCCAGTCAG) and HACdelR (5'-ATTATATTCTGGGAGCGCCAAAG AAATTTAGACTTTATGAACTTCAACATCATCTCCTAAAATCGAAAAAAA ATCATCAAAGTCCAACTGAAATGATTCTATTGGCTCTGCTGGCTAGCAC TAAAGGGAACAAAAGC) with the plasmid templates pLAL2 or pLHL, respectively (Dennison et al., 2005). The hac1::LAL and hac $1:$ :LHL disruption cassettes delete from +120 to +1032 of the 1074 bp HAC1 ORF. These cassettes were transformed sequentially into C. albicans BWP17 to disrupt both alleles of the HAC1 gene and generate a $\mathrm{HAC1}^{-}, \mathrm{ARG}^{+}, \mathrm{HIS}^{+}, \mathrm{URI}^{-}$mutant. An arg4::MET3-creURA3 cassette was transformed into this mutant and the cre resolvase activated on medium lacking methionine/cysteine (Dennison et al., 2005). This generated the $\mathrm{HAC1}^{-}, A R G^{-}, \mathrm{HIS}^{-}, \mathrm{URI}^{-}$mutant,
TW01 (hac1::loxP/hac1::loxP: Table 1), the genotype of which was confirmed by PCR and Southern hybridization.

To reintroduce HAC1 into C. albicans TW01, the HAC1 locus was PCR amplified using the primers HAC1SACIF (5'-GAGAGCTCCCAAT TTTCGTGCCGTAGG) and HAC1SACIIR (5'-GACCGCGGTTTAGTGGTG GCTGATTTTT) (SacI and SacII sites underlined) and cloned into the plasmid CIp30 (Dennison et al., 2005) to create CIp30-HAC1 (hac1). CIp30, which is a derivative of CIp10 (Murad et al., 2000), contains the URA3 HIS1 and ARG4 markers. CIp30-HAC1 was linearized with StuI, transformed into C. albicans to create the HAC1-reintegrant strain TWO4 (hac1/hac1/HAC1 Table 1). The integration of CIp30-HAC1 at the RPS1 locus in TW04 was confirmed by PCR using the primers 5'-CACCACTATCATAACCAAGAG and 5'-ATTTGTAATGG GGAATCATGG. The control strains, TW02 and TW03, were generated by transforming the parental strain (BWP17) and the hac1/ hac1 mutant (TW01) with the empty CIp30 plasmid (Table 1), respectively.

\subsection{Microscopy}

The morphologies of $C$. albicans cells were examined using light and fluorescence microscopy. Cells were grown overnight in YPD, $30{ }^{\circ} \mathrm{C}$ with shaking, diluted to $\mathrm{OD}_{600}=0.5$ in fresh YPD medium with $20 \%(\mathrm{v} / \mathrm{v})$ foetal calf serum. Cultures were incubated at $37^{\circ} \mathrm{C}$ and cells visualised by light microscopy every hour. To analyse the effect of temperature and $\mathrm{pH}$ shift, single colonies were isolated and used to inoculate the Soll's medium ( $\mathrm{pH} \mathrm{4.5)} \mathrm{(Buffo}$ et al., 1984). Cultures were grown overnight in Soll's medium, $25^{\circ} \mathrm{C}$ with shaking. Five millilitres of this culture was used to inoculate $50 \mathrm{ml}$ Soll's medium ( $\mathrm{pH} \mathrm{6.5)}$ ) prewarmed to $37^{\circ} \mathrm{C}$ for $5 \mathrm{~h}$. To differentiate the true hyphae from pseudohyphae, $C$. albicans cells were stained with $0.1 \%(\mathrm{w} / \mathrm{v})$ Calcofluor white to visualize septa through their relatively high chitin content. Cell morphology was analysed using a Zeiss imaging microscope mounted with a $35 \mathrm{~mm}$ Nixon Axiocam camera. The morphology index (Mi) of C. albicans cells was determined from their maximum length $(l)$, maximum diameter $(d)$ and septal diameter $(s)$ in the ratio $(l \cdot s) / d^{2}$, as described by Merson-Davis and Odds (1989).

\subsection{Stress sensitivity}

The sensitivities of C. albicans strains to DTT, tunicamycin, Calcofluor white, and Congo red (Sigma) were assayed by spotting 10 -fold serial dilutions of freshly grown mid-exponential cells onto YPD agar containing these agents at the specified range of concentrations. Growth was monitored after $48 \mathrm{~h}$ at $30^{\circ} \mathrm{C}$.

\subsection{Complementation tests}

We tested the ability of various C. albicans HAC1 cDNA species to complement $S$. cerevisiae hac1 phenotypes using the strains BY4741 (MATa his3 $\Delta 1$ leu2 $\Delta 0$ met15 $\Delta 0$ ura3 $\Delta 0$ ) and the S. cerevisiae hac1 mutant derived from BY4741 (EUROSCARF, Frankfurt, Germany) (Table 1). The expression vector pVTU260 (Melcher, 2000: EUROSCARF) was used to express C. albicans HAC1 CDNAs in S. cerevisiae. cDNAs containing unspliced and spliced versions of CaHAC1 were amplified by PCR using the primers CaHAC1NHEIF (5'-GAGCT AGCATGGAGTTAACTGTTG) and CaHAC1NCOIR (5'-GACCATGGCCC GCCAAACA) to create restriction sites (underlined), just before and after the start and stop codons, respectively. The resulting PCR products ( $1217 \mathrm{bp}$ and $1198 \mathrm{bp}$ ) were digested with NheI and NcoI and cloned into pVTU260 between the ADH1 promoter and terminator sequences to create pVTUTW01 (unspliced HAC1) and pVTUTW02 (spliced HAC1), which were verified by DNA sequencing. pVTU260, pVTUTW01 and pVTUTW02 were transformed into S. cerevisiae (Gietz and Woods, 2002). The 
transformants were confirmed by PCR using the primers, 5'-CTCGT TCCCTTTCTTCCTTG and 5'-GAACCAAACTTAT, and their sensitivities to the UPR stresses, DTT and tunicamycin, tested as described above.

\subsection{Transcription profiling}

Transcript profiling was performed on the C. albicans strains BWP17 (HAC1/HAC1) and TW01 (hac1/hac1) as described previously (Enjalbert et al., 2006). The strains were cultured to $\mathrm{OD}_{600}=0.5$ in YPD supplemented with uridine at $30^{\circ} \mathrm{C}$, at $200 \mathrm{rpm}$, and then divided into two parts: one for ER stress and one control (carrier). Cells were exposed to DTT ( $5 \mathrm{mM}$ ) or tunicamycin $[4 \mu \mathrm{g} / \mathrm{ml}(4.73 \mu \mathrm{M})]$ for $1 \mathrm{~h}$, collected by centrifugation, snap frozen in liquid $\mathrm{N}_{2}$, disrupted using a microdismembrator (Braun, Melsungen, Germany) and RNA prepared as described previously (Hauser et al., 1998). To analyse the effect of HAC1 deletion, C. albicans strains BWP17 (HAC1/HAC1) and TW01 (hac1/hac1) were cultured to $\mathrm{OD}_{600}=0.5$ in YPD supplemented with uridine at $30^{\circ} \mathrm{C}$, at $200 \mathrm{rpm}$, collected by centrifugation, snap frozen in liquid $\mathrm{N}_{2}$, disrupted using a microdismembrator and RNA prepared as described above. Cy3- and Cy5-labeled cDNAs were prepared from total RNA, and the probes were hybridized with whole genome microarrays containing ca. 6000 C. albicans genes (Eurogentec, Seraing, Belgium). Slides were scanned using a ScanArray Lite scanner (PerkinElmer Life Sciences, Beaconsfield, United Kingdom) and quantified using QuantArray software (version 2.0). Preliminary normalization and logarithmic transformation were performed with Excel 2000 (Microsoft). Data normalization and analysis were performed using GeneSpring (Silicon Genetics, Redwood City, CA), and statistical analysis was performed using SAM (Significance Analysis of Microarrays; Tusher et al., 2001). Expression ratios were calculated by comparing stressed cells with their unstressed control in wildtype and mutant strains independently. For HAC1 deletion analysis, expression ratios were calculated by comparing the TW01 cells with wild-type (BWP17) cells. Data from at least three independent biological replicates were used for each analysis. The data are available at www.ebi.ac.uk/arrayexpress (E-MEXP-1307).

Genes up-regulated due to DTT and tunicamycin treatments $(\geqslant 1.5$-fold) were considered as putative ER stress-induced genes. Genes down-regulated due to HAC1 deletion (>1.5-fold) were considered as Hac1-dependent genes without ER stress.

\section{Results}

\subsection{C. albicans HAC1}

A presumptive HAC1 locus (CA0457) was identified in the C. albicans genome sequence (http://genolist.pasteur.fr/CandidaDB/) via homology to the $S$. cerevisiae HAC1 gene (YFL031w). The translated sequence of this putative HAC1 locus displays strong sequence similarity to other fungal Hac1 protein sequences in the DNA-binding region, but the sequence similarity is limited outside this region (Fig. 1A). Similar observations have been made when comparing other transcription factors in C. albicans and S. cerevisiae. These functional orthologues often display limited sequence similarity outside their DNA-binding domains (Fig. 1A) (e.g. Stoldt et al., 1997; Tripathi et al., 2002; Martchenko et al., 2007).

During the UPR in other fungal systems HAC1 mRNA is activated via an atypical splicing event (Cox and Walter, 1996; Mori et al., 1996; Saloheimo et al., 2003; Mulder et al., 2004). Therefore, to test whether CA0457 represents the C. albicans HAC1 gene, we examined the splicing of the CA0457 transcript in response to the ER stresses, DTT or tunicamycin. RT-PCR was performed across the putative HAC1 mRNA intron using cDNA prepared from ER stressed and unstressed cells. Splicing of the intron following ER stress was confirmed by DNA sequencing of the shorter RT-PCR products and the intron was shown to be $19 \mathrm{bp}$ (Fig. 1B). This splicing event alters the C-terminal amino acid sequence of the Hac1 protein. DNA sequencing also confirmed that the $C$. albicans HAC1 gene was devoid of CUG codons. Furthermore, we identified that the sequence of HAC1 is incomplete and the full HAC1 genome sequence data have been submitted to the GenBank database under Accession No. EF655649. Intron borders and splice sites of the $S$. cerevisiae HAC1 and filamentous fungal (Aspergillus niger) hacA are well conserved (Calfon et al., 2002), and these conserved bases were also found at the borders of the C. albicans HAC1 (Fig. 1C). We examined the HAC1 mRNA splicing event in yeast and hyphal cells. There was a clear increase in the abundance of a shorter RT-PCR product following ER stress in yeast cells, consistent with the splicing of the intron from this region of the transcript (Fig. 2A). HAC1 mRNA splicing was only detected in hyphae following exposure to ER stress (Fig. 2B).

We asked whether HAC1 mRNA is spliced following amino acid starvation in $C$. albicans. No detectable splicing of the 19 bp HAC1 mRNA intron was observed in cells treated with 3AT which imposes histidine starvation and activates general amino acid control in C. albicans (Tripathi et al., 2002) although splicing was evident in the presence of DTT (Fig. 2B). Furthermore, HAC1 mRNA splicing was not enhanced further by simultaneous exposure of C. albicans cells to DTT and 3AT (Fig. 2B). Note that the effects of exposure to tunicamycin were similar to those of DTT (data not shown).

We performed complementation tests to determine whether CA0457 is a functional homologue of S. cerevisiae HAC1. cDNAs containing the unspliced $\left(H A C 1^{\mathrm{u}}\right)$ and spliced $\left(H A C 1^{\mathrm{i}}\right)$ versions of $C$. albicans HAC1 were cloned into the S. cerevisiae $A D H 1$ expression vector, pVTU260 to generate pVTUTW01 and pVTUTW02, respectively. These plasmids were transformed into an $S$. cerevisiae hac1 null mutant strain and these transformants tested for their sensitivity to DTT and tunicamycin (Fig. 3). As expected, the $S$. cerevisiae hac1 strain was hypersensitive to DTT and tunicamycin compared with the isogenic wild-type parental strain. This phenotype was partially suppressed by expression of spliced $C$. albicans HAC1 sequence (pVTUTW02) into $S$. cerevisiae hac1 cells, but not by the unspliced $C$. albicans HAC1 cDNA (pVTUTW01). We conclude that C. albicans HAC1 is a functional homologue of $S$. cerevisiae $H A C 1$, but that $S$. cerevisiae is probably unable to process accurately the non-spliceosomal intron in the C. albicans HAC1 gene.

\subsection{C. albicans HAC1 UTR}

In filamentous fungi, ER stress induces truncation of the HAC1 mRNA in the $5^{\prime}$-untranslated region as well as excision of the non-conventional intron, but this $5^{\prime}$ truncation is not observed in S. cerevisiae (Rüegsegger et al., 2001; Mulder et al., 2004). We examined this in $C$. albicans by RACE-PCR with RNA isolated from C. albicans cells treated with DTT and from untreated control cells. Three HAC1 transcriptional start sites were identified in DTT-treated cells, whereas only one start site was detected in unstressed cells (Fig. 4). The unstressed cells produced a longer mRNA, with only one transcription starting point compared to three different start positions in DTT stressed cells which are 41, $74(41+33)$, and $92(74+18)$ nucleotides downstream of the non-stressed transcriptional start site. The extended $5^{\prime}$-untranslated region observed in unstressed cells is predicted to form more stable RNA secondary structures $(\Delta G=-16.9 \mathrm{kcal} / \mathrm{mol})$ than the shorter $5^{\prime}$-untranslated regions in ER stressed cells $(\Delta G=2.1 \mathrm{kcal} / \mathrm{mol})$. Therefore $H A C 1$ transcripts in ER stressed cells have truncated 5'-untranslated regions. 


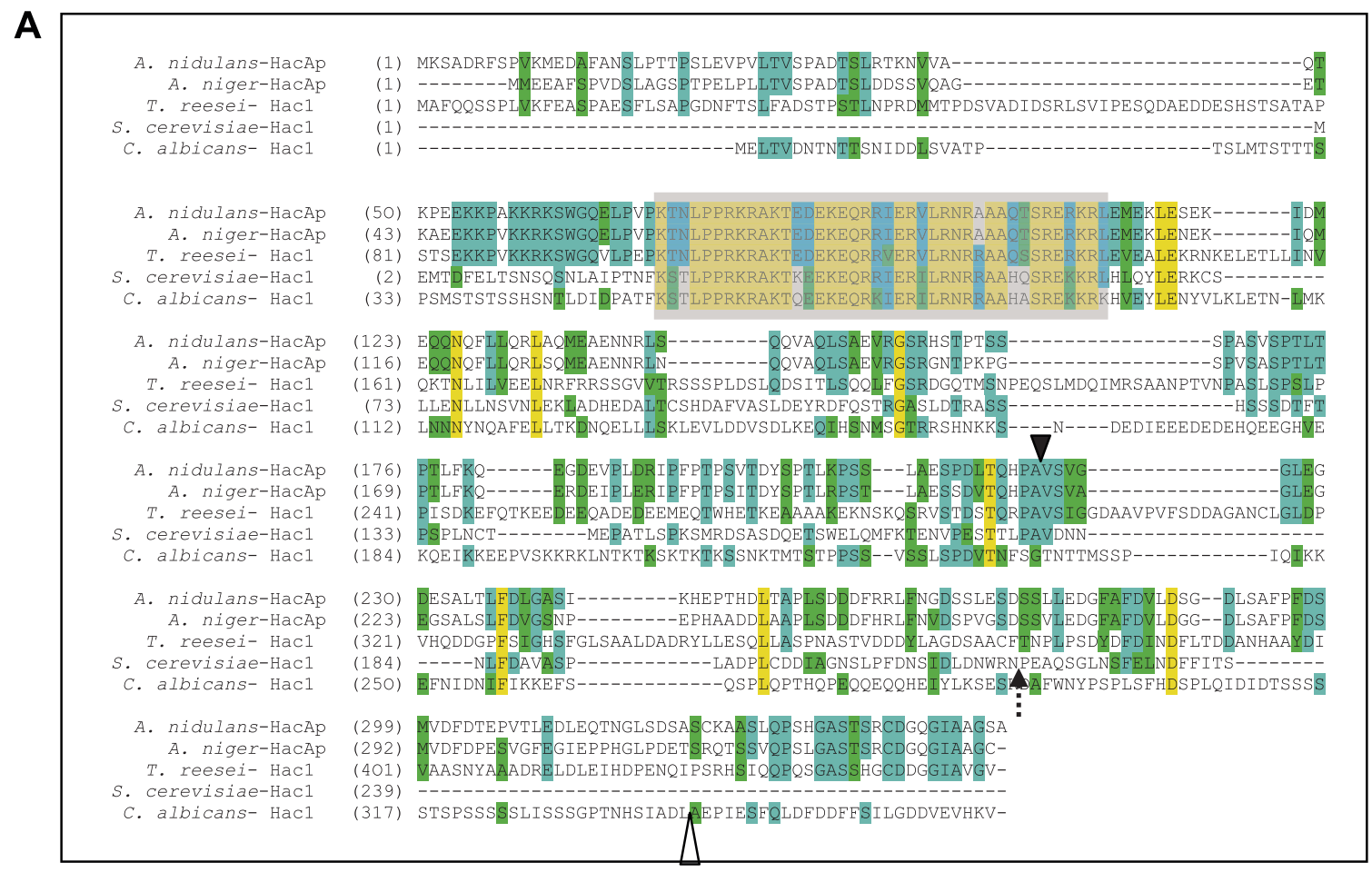

B

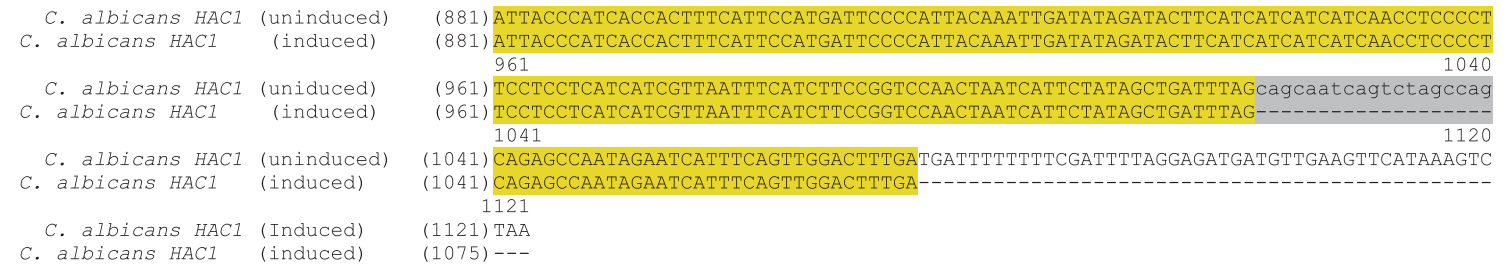

C

S. cerevisiae $H A C 1$

A. niger hacA

C. albicans HAC1

Consensus

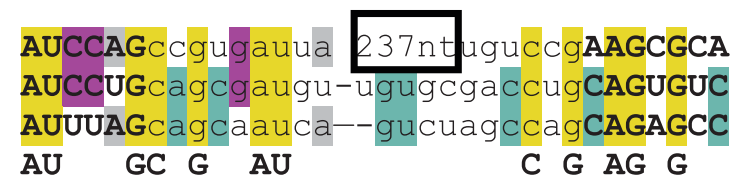

Fig. 1. (A) Alignment of the Hac1 protein sequences from Aspergillus nidulans, A. niger, S. cerevisiae, T. reesei and C. albicans. Note that C. albicans Hac1 has similarity to the other proteins only in the DNA-binding domain area (shaded). The positions of the atypical intron in A. nidulans, A. niger and T. reesei ( $\mathbf{\nabla})$ S. cerevisiae ( $\mathbf{\Delta})$ and C. albicans ( $\triangle$ ) sequences are indicated. (B) DNA sequence alignment of the C. albicans HAC1 (induced) and HAC1 (uninduced) gene. The 19bp atypical intron is indicated in lower case. (C) Alignment of the mRNA sequence surrounding the intron in S. cerevisiae HAC1, A. niger hacA and C. albicans HAC1. Intron flanks are indicated by upper case. $237 \mathrm{nt}$ refers to 237 nucleotides out of the $252 \mathrm{nt}$ present in the S. cerevisiae HAC1 intron.

\subsection{C. albicans HAC1 and ER stress resistance}

We generated a homozygous C. albicans hac1/hac1 null mutant to test whether Hac1 is required for ER stress resistance. Both HAC1 alleles in this diploid fungus were sequentially deleted, removing nucleotides +121 to +1032 of the 1074 bp ORF. The ARG4 and HIS1 markers used in this process were removed by site-specific recombination via the Cre-loxP system (Dennison et al., 2005). This allowed the generation of a well-controlled isogenic set of wild-type (HAC1/HAC1: TW02), mutant (hac1/hac1: TW03) and reintegrated (hac1/hac1/HAC1: TW04) strains in which the ARG4, HIS1 and URA3 markers are all located at the same genomic location (Table 1 ). In this way we avoided the complication that marker position effects may influence some phenotypes in C. albicans (Lay et al., 1998; Sundström et al., 2002; Brand et al., 2004).

The behaviours of these wild-type, mutant and reintegrated strains were compared following ER stress on YPD agar plates. As expected (Chaffin, 1985), wild-type C. albicans cells were sensitive to tunicamycin. We observed that Hac1 inactivation reproducibly increased the sensitivity of $C$. albicans cells to tunicamycin and DTT on plates (Fig. 5) and in liquid culture (not shown). These phenotypes were suppressed by the reintegration of a wild-type HAC1 gene, confirming that Hac1 is required for ER stress resistance in $C$. albicans. This is consistent with the situation in S. cerevisiae (Schröder and Kaufman, 2005a).

\subsection{The genome-wide impact of Hac1 in C. albicans}

The genome-wide role of Hac1 in C. albicans was examined by transcript profiling. We compared the genome-wide expression profiles of wild-type and hac1/hac1 yeast cells in following exposure to the ER stresses, DTT and tunicamycin (Supplementary data Part A). At least three independent replicates were performed for each experimental condition and genes that displayed statistically significant changes in expression level ( $\geqslant 1.5$-fold Supplementary data Part B) were identified using SAM (Materials and Methods). Changes in transcript levels were verified by quantitative real-time PCR for six genes under stress conditions (SEC61:CA3197), ALS12 


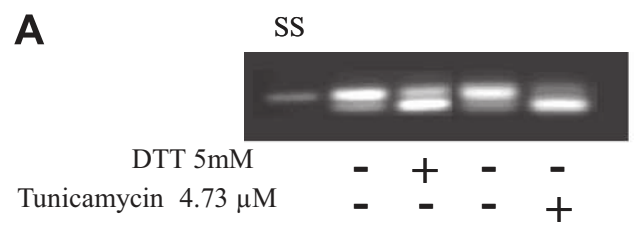

B

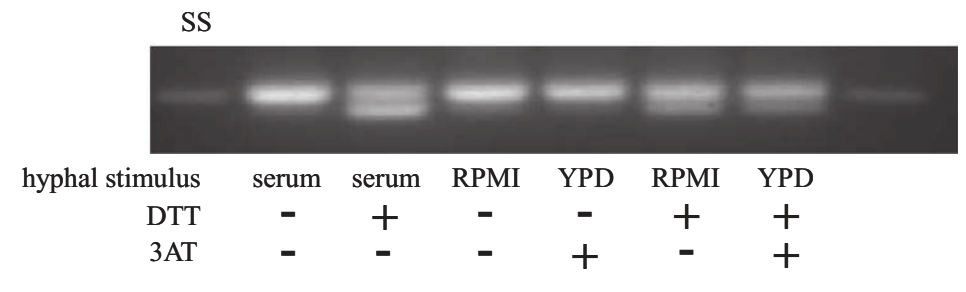

Fig. 2. Splicing of the C. albicans HAC1 mRNA non-conventional intron under stress conditions. (A) RT-PCR across the HAC1 mRNA intron from total RNA extracted from C. albicans yeast-like cells and exposed to DTT ( $5 \mathrm{mM}$ ) or tunicamycin $(4.73 \mu \mathrm{M})$. A size standard (SS) of 100 bp is included. The size difference between the upper (non-spliced) and lower (spliced) from of cDNA is 19 bp. (B) RT-PCR across the C. albicans HAC1 mRNA intron from total RNA extracted from C. albicans hyphae: YPD + 20\% serum (water control), YPD + 20\% serum with 5 mM DTT, RPMI-1640 (water control), YPD + 30 mM 3 AT, RPMI-1640 with 5 mM DTT, YPD + 30 mM 3 AT with 5 mM DTT.

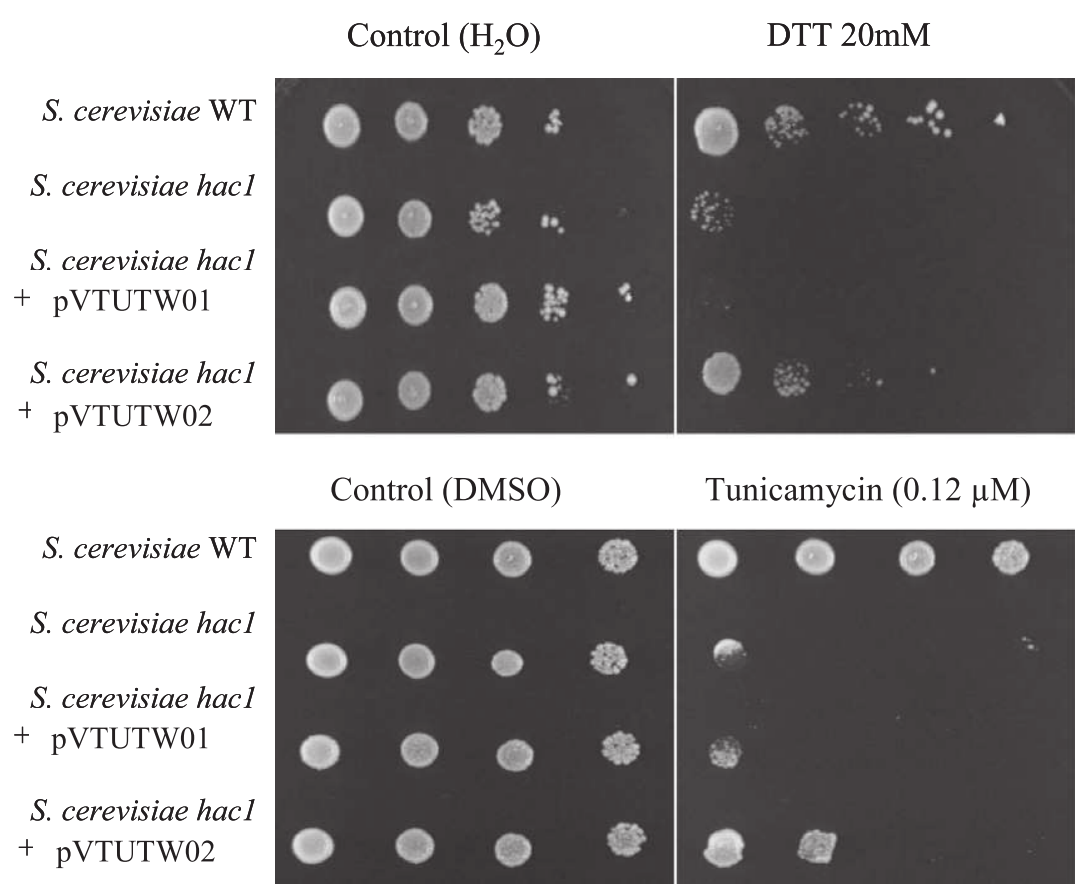

Fig. 3. Spliced C. albicans HAC1 complements the defects of a S. cerevisiae hac1 mutant. Growth of the yeast disruptants, transformed with constructs pVTUTW01 and pVTUTW02, grown on YPD with and without UPR stress inducing agents. C. albicans HAC1 ${ }^{\mathrm{u}}$ and $H A C 1^{\mathrm{i}}$ sequences were inserted into plasmid pVTU260 to produce pVTUTW01 and pVTUTW02, respectively. ('i' and 'u' indicates the induced and uninduced form of HAC1 mRNA in C. albicans).

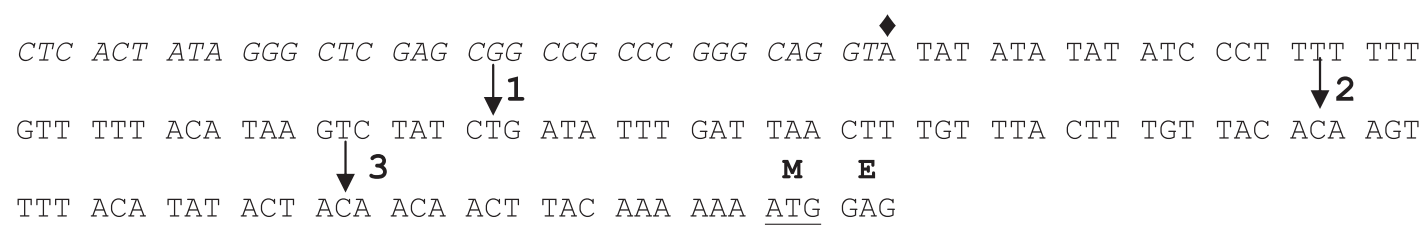

Fig. 4. Overview of the sequence at the 5'UTR of the C. albicans HAC1 gene. The primer used to identify the HAC1 5'-end used is shown by italics. The $5^{\prime}$-end of the rapid amplification of CDNA ends (RACE)-PCR products from an untreated control sample is shown by a diamond ( ) and the splice sites of the RACE-PCR products from a DTTtreated sample shown by vertical arrows $(\downarrow)$ and numbered accordingly. The translation start codon is underlined. M and E are the first two amino acids in the Hac1 sequence.

(ALS2:CA0413), ALS5 (CA2852), YSY6 (CA1267), PMT4 (CA4314), EROI (CA2076) and GPI10 (CA4764) (Supplementary data, Part C).

Selected sets of genes were reproducibly and significantly upregulated when wild-type $C$. albicans cells were exposed to DTT or tunicamycin. 523 C. albicans genes (8\% of the total number of predicted ORFs) were up-regulated at least 1.5 -fold in response to DTT, and 641 genes were up-regulated in response to tunicamycin. Of these genes, 393 were up-regulated in response to both DTT and tunicamycin. These 393 genes were classified as ER stress genes, thereby defining the genome-wide transcriptional response 


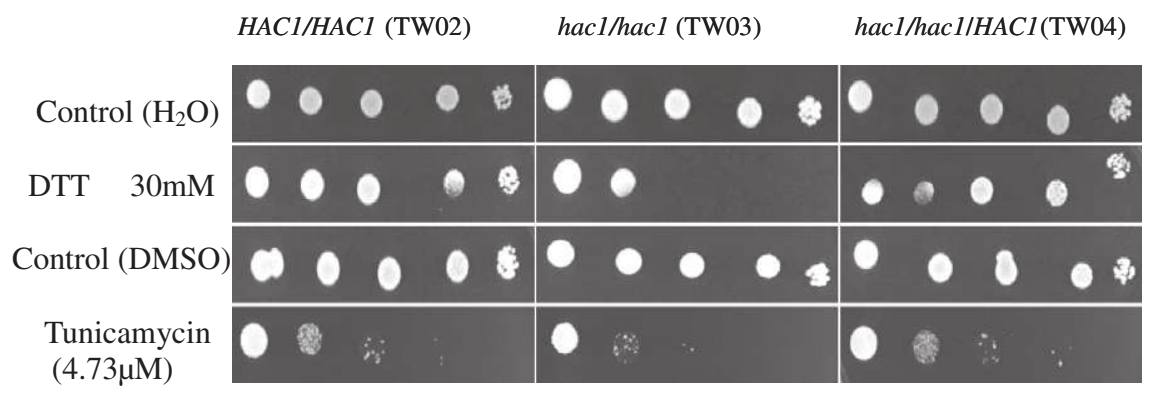

Fig. 5. Sensitivity of $C$. albicans hac1/hac1 cells to ER stress. Growth of C. albicans strains HAC1/HAC1 (TW02), hac1/hac1 (TW03) and hac1/hac1/HAC1 (TW04) on YPD agar medium containing $30 \mathrm{mM}$ DTT or $4.73 \mu \mathrm{M}$ tunicamycin $(4 \mu \mathrm{g} / \mathrm{ml})$.

during ER stress in C. albicans. These included HAC1 itself, this transcript being 2 -fold and 2.9-fold up-regulated in response to DTT and tunicamycin, respectively (Supplementary data, Part B). Other C. albicans genes were regulated specifically by DTT or tunicamycin.

We analysed the functional categories that displayed statistically significant enrichment in these subsets of genes compared with the genome as whole (Supplementary data, Part D). Significantly, functional categories relating to protein secretion and cell wall biosynthesis were up-regulated in wild-type $C$. albicans cells following exposure to DTT and tunicamycin. Clearly, Hac1 contributes to this regulation, because much of this regulation was lost or reduced in hac1/hac1 cells, particularly for DTT-treated cells.

These observations were reinforced by a closer examination of the behaviour of Hac1-dependent genes under these stress conditions. 252 genes were identified as up-regulated ( $\geqslant 1.5$-fold differential regulation) in response to both DTT and tunicamycin and were Hac1-dependent (at least 1.5-fold expression ratios of WT/ hac1 in either condition) (Supplementary Data Part E). Within this list, $C$. albicans genes that showed $\geqslant 1$.5-fold differential regulation in response to both DTT and tunicamycin and were Hac1-dependent (at least 1.5-fold expression ratios of WT/hac1 in both conditions) in their transcription were listed according to functional category (Fig. 6). These genes were defined as genes regulated by the UPR. Seventy-nine genes are secretion-related and up-regulated in a Hac1-dependent manner in C. albicans under stress conditions. One hundred and three genes were similarly up-regulated in S. cerevisiae (Travers et al., 2000). Only 12 genes identified as Hac1-regulated in C. albicans were also found to be Hac1p-regulated in S. cerevisiae; these are indicated in Fig. 6. Furthermore, there were seven genes identified as having no clear homologues in the $S$. cerevisiae genome database. Down-regulated genes are catalogued in Supplementary Data Part F.

Transcriptional profiles of WT and hac1/hac1 cells were also compared when cells were grown in yeast form in rich (YPD) medium in the absence of either DTT or tunicamycin. From the array data, 126 genes were transcriptionally-dependent on HAC1 at $>1.5$-fold and 66 of those genes had homologues in S. cerevisiae. Of those genes, the following have functionality in the secretory process (CHC1 (CA0801), COP1 (CA0606), MYO2 (CA5247), PEX14 (CA0573), SEC14 (CA5398), SEC27 (CA2033), SRP54 (CA5440), SRP72 (CA2519) (Supplementary data Parts G). None of the ALS genes that are regulated by Hac1 under stress conditions were identified under non-stress conditions.

\subsection{C. albicans HAC1, the cell wall and morphogenesis}

Transcript profiling studies suggested that Hac1 influences the transcription of genes, at least under stress conditions, involved in cell wall biogenesis and in secretory and vesicle trafficking pro- cesses. We reasoned therefore, that $C$. albicans cells might display phenotypes associated with cell wall defects. We tested this by exposing wild-type (TW02), hac1/hac1 mutant (TW03) and HAC1reintegrant (TW04) strains to cell wall-perturbing agents. When these strains were plated on YPD agar containing Congo red $(250 \mu \mathrm{g} / \mathrm{ml})$ and Calcofluor white $(30 \mu \mathrm{g} / \mathrm{ml})$ (Bates et al., 2005), it was evident that $C$. albicans hac1/hac1 cells are more sensitive to Congo red and Calcofluor white than the isogenic control strains (Fig. 7). Wild-type and reintegrant strains were sensitive to these cell wall-perturbing agents at higher concentrations compared to the hac1/hac1 mutant strain (data not shown). This is consistent with the idea suggested by our microarray analyses that Hac1 influences the synthesis of cell wall components.

The morphologies of wild-type (TW02), hac1/hac1 mutant (TW03) and HAC1-reintegrant (TW04) cells were examined following serum-stimulation (Fig. 8). The hac1/hac1 mutant displayed significant morphological defects that were suppressed by the reintroduction of HAC1 (Fig. 8A and B). The morphologies of mutant and control cells were quantified using the morphological index (Merson-Davis and Odds, 1989). Hyphal development was reduced from about $80 \%$ to $14 \%$ in the hac/hac1 mutant, with a concomitant increase in pseudohyphal and budding cells under these conditions (Fig. 8C). As shown in Fig. 8D, Growth at $37^{\circ} \mathrm{C}$ and near to neutral $\mathrm{pH}$ highly favoured pseudohyphae formation in all three strains (Sudbery, 2001). Nevertheless, the formation of hyphae in hac1/hac1 cells was reduced by $23 \%$ compared to wild-type and reintegration strains (Fig. 8D). This confirmed an impact of Hac1 on C. albicans morphology, revealing a general reduction in polarized growth in hac1/hac1 cells.

We also noted that filamentous hac1/hac1 cells formed smaller and less sticky flocks compared with their isogenic controls (Fig. $8 \mathrm{E}$ ), suggesting that Hac1 inactivation affected adhesin function at the cell surface. This was consistent with our observation that the $C$. albicans genes that are up-regulated in a Hac1-dependent manner during UPR stress include several adhesins (ALS4 [CA1528], ALS5 [CA2852], ALS12 [ALS2:CA0413], ALS10 [ALS3: CA0448]: Hoyer, 2001) and protein mannosyltransferases that are known to affect the functionality of $C$. albicans adhesins (PMT1, PMT2, PMT4-6: Timpel et al.,1998, 2000). Strain comparisons in the absence of ER stress were only possible for yeast cells, and expression of the adhesion genes was not identified as being Hac1-dependent.

\section{Discussion}

We have shown that $C$. albicans HAC1 mRNA carries a non-conventional intron whose length (19 bp) is similar to that observed in filamentous fungi and therefore distinct from the $250 \mathrm{bp}$ intron in HAC1 from S. cerevisiae. This C. albicans HAC1 mRNA intron is removed in response to ER stress, as might have been expected based 


\begin{tabular}{|c|c|c|c|c|c|c|c|}
\hline & $\begin{array}{c}1 \\
W T^{1}\end{array}$ & $\begin{array}{r}2 \\
w T\end{array}$ & $\begin{array}{c}3 \\
h a c 1\end{array}$ & $\begin{array}{c}4 \\
h a c 1\end{array}$ & $\begin{array}{r}5 \\
\text { ratio }\end{array}$ & $\begin{array}{r}6 \\
\text { of } W T /\end{array}$ & hac1 /hac1) \\
\hline & DTT & Tun & DTT & Tun & DTT & Tun & Common name \\
\hline \multicolumn{8}{|c|}{ Transl ocation } \\
\hline CA3197* & 3.1 & 3.8 & 1.1 & 0.8 & 2.8 & 4.9 & SEC61 \\
\hline CA1267 & 2.7 & 4.7 & 1.3 & 1.1 & 2.0 & 4.4 & YSY6 \\
\hline CA2425* & 2.2 & 2.8 & 0.8 & 1.1 & 2.7 & 2.5 & SEC 12 \\
\hline CA5452 & 1.7 & 3.3 & 1.1 & 1.6 & 1.6 & 2.1 & SEC 11 \\
\hline CA0958* & 1.8 & 2.3 & 1.3 & 1.0 & 1.5 & 2.4 & SEC 24 \\
\hline \multicolumn{8}{|c|}{ Glyco sylation/ Mod ification } \\
\hline CA4424* & 1.7 & 2.2 & 0.7 & 0.5 & 2.6 & 4.1 & PMT1 \\
\hline CA4314 & 2.6 & 3.0 & 0.9 & 0.9 & 3.0 & 3.3 & PMT4 \\
\hline CA0503 & 1.6 & 1.5 & 0.6 & 0.7 & 2.5 & 2.2 & PMT6 \\
\hline CA5003* & 2.8 & 2.4 & 1.0 & 1.2 & 2.7 & 2.1 & MCD4 \\
\hline CA4528 & 1.6 & 2.2 & 1.0 & 1.1 & 1.6 & 2.0 & STT3 \\
\hline CA2612* & 3.1 & 3.5 & 1.3 & 1.9 & 2.3 & 1.8 & GAA1 \\
\hline CA2980 & 2.1 & 1.8 & 1.0 & 1.2 & 2.1 & 1.5 & GOG 5 \\
\hline CA5610 & 1.8 & 1.6 & 0.8 & 0.9 & 2.1 & 1.9 & PMR 1 \\
\hline CA5144 & 2.4 & 1.6 & 0.9 & 1.0 & 2.6 & 1.5 & IPF1019 \\
\hline CA1146 & 3.6 & 1.8 & 1.0 & 0.9 & 3.5 & 2.0 & CWH8 \\
\hline CA5894* & 1.7 & 1.5 & 0.4 & 0.4 & 4.2 & 3.9 & PMT2 \\
\hline \multicolumn{8}{|c|}{ Protein Folding } \\
\hline CA0457 & 2.0 & 2.9 & 1.0 & 1.0 & 1.9 & 3.0 & HAC1 \\
\hline CA1583 & 2.3 & 1.9 & 1.0 & 1.4 & 2.3 & 1.4 & ROT1 \\
\hline \multicolumn{8}{|c|}{ Protein degradation } \\
\hline CA0549 & 1.5 & 1.7 & 1.0 & 1.1 & 1.5 & 1.6 & SAP98 \\
\hline CA5322 & 5.1 & 2.8 & 1.5 & 1.6 & 3.5 & 1.8 & PRB1 \\
\hline CA0881 & 2.0 & 2.7 & 1.2 & 1.8 & 1.6 & 1.5 & IPF16965 \\
\hline CA5735 & 1.7 & 1.9 & 0.9 & 1.2 & 1.8 & 1.5 & IPF2878 \\
\hline CA4105 & 3.6 & 2.8 & 2.2 & 1.9 & 1.6 & 1.5 & SMT3 \\
\hline \multicolumn{8}{|c|}{ Vesicle trafficking/Transport } \\
\hline CA2353 & 1.8 & 1.6 & 1.2 & 0.6 & 1.5 & 2.6 & VPS13 \\
\hline CA1896* & 2.5 & 3.9 & 1.5 & 2.3 & 1.7 & 1.7 & ERD2 \\
\hline CA4739 & 2.8 & 3.2 & 1.1 & 1.6 & 2.5 & 1.9 & IPF4498 \\
\hline CA3230 & 1.5 & 1.7 & 1.0 & 1.1 & 1.5 & 1.5 & EMP24 \\
\hline \multicolumn{8}{|c|}{ Lipid /Inositol meta bolism } \\
\hline CA3211 & 3.2 & 5.5 & 1.5 & 1.5 & 2.2 & 3.6 & IPF19977 \\
\hline CA5986 & 8.6 & 2.2 & 2.5 & 0.9 & 3.4 & 2.4 & INO1 \\
\hline CA1956 & 4.2 & 1.6 & 1.7 & 1.0 & 2.5 & 1.7 & $E R G 3$ \\
\hline CA3590 & 3.0 & 1.7 & 1.7 & 1.0 & 1.8 & 1.7 & ARE2 \\
\hline CA0863 & 4.2 & 1.8 & 2.3 & 1.1 & 1.9 & 1.6 & $\operatorname{ITR2}$ \\
\hline CA2934 & 2.0 & 1.7 & 1.2 & 1.1 & 1.7 & 1.5 & IPF11515 \\
\hline \multicolumn{8}{|c|}{ Cell wall associated proteins } \\
\hline CA0413 & 3.5 & 2.3 & 0.9 & 0.8 & 3.8 & 2.8 & ALS2 \\
\hline CA1528 & 3.5 & 2.1 & 0.9 & 0.8 & 3.8 & 2.7 & ALS4 \\
\hline CA2852 & 1.8 & 1.6 & 1.1 & 0.9 & 1.6 & 1.8 & ALS5 \\
\hline CA0448 & 2.0 & 2.3 & 1.4 & 1.3 & 1.5 & 1.7 & $A L S 3$ \\
\hline CA0882 & 3.1 & 2.1 & 1.5 & 1.3 & 2.0 & 1.7 & PHR 3 \\
\hline CA0356* & 1.8 & 3.7 & 1.0 & 1.2 & 1.7 & 3.0 & IPF2532 \\
\hline CA5468 & 1.7 & 1.7 & 1.1 & 1.1 & 1.6 & 1.5 & IFF7 \\
\hline CA3613* & 2.1 & 1.7 & 1.0 & 1.0 & 2.0 & 1.8 & SPF1 \\
\hline CA2714 & 7.2 & 4.0 & 2.4 & 1.9 & 3.0 & 2.1 & IFF2 \\
\hline
\end{tabular}

Fig. 6. Impact of Hac1 inactivation upon the regulation of $C$. albicans genes during ER stress. C. albicans genes showing differential regulation in response to DTT and tunicamycin and having homologues in S. cerevisiae were clustered according to functional category. Columns (1-4) from left to right correspond to: (1) DTT-treated versus untreated wild-type cells (BWP17); (2) tunicamycin-treated (Tun) versus untreated wild-type cells; (3) DTT-treated versus untreated hac1/hac1 (TW01) cells; (4) tunicamycin-treated versus untreated hac1/hac1 (TW01) cells. Two scale bars are presented at the bottom of the figure. The influence of Hac1 on these expression patterns was estimated by dividing the fold regulation for a particular gene under a particular condition in hac1/hac1 (TW01) cells by the corresponding fold-regulation in wild-type cells (columns 5 and 6). Expression ratios are indicated by the upper of the two scale bars (red, up-regulation; green, down-regulation). The impact of Hac1 upon this regulation was assessed by dividing the fold regulation for a specific gene in wild-type cells by the corresponding regulation in hac1/hac1 cells; (5) DTT stress; (6) tunicamycin stress. Those genes whose transcription was affected more than 1.5 -fold by DTT or tunicamcyin and had a ratio of $\geqslant 1.5$-fold expression change (WT vs $\Delta$ hac 1 ) were defined as genes regulated by the UPR in a Hac1-dependent manner. Of these genes, 12 were identified in S. cerevisiae (Travers et al., 2000) as being Hac1-dependent UPR genes: they are indicated by an asterisk. Genes identified as having no clear homologues in S. cerevisiae are highlighted in bold in the right panel. 


\begin{tabular}{|c|c|c|c|c|c|c|c|}
\hline \multicolumn{8}{|c|}{ Cellular transp ort } \\
\hline CA3895 & 4.9 & 1.7 & 2.8 & 0.5 & 1.7 & 3.6 & CDR4 \\
\hline CA0609 & 2.1 & 3.2 & 1.2 & 1.4 & 1.8 & 2.3 & $C D R 11$ \\
\hline CA3154 & 4.4 & 1.9 & 1.7 & 1.2 & 2.6 & 1.6 & FUN34 \\
\hline CA2792* & 1.6 & 1.5 & 0.9 & 1.0 & 1.8 & 1.5 & $T R K 1.3 f$ \\
\hline CA0954 & 1.9 & 3.2 & 1.2 & 2.2 & 1.6 & 1.5 & IPF13162 \\
\hline CA4669 & 3.1 & 3.1 & 2.0 & 2.1 & 1.6 & 1.5 & AVT \\
\hline CA0981 & 2.0 & 2.0 & 1.2 & 1.4 & 1.6 & 1.5 & GAP4 \\
\hline CA2435 & 2.8 & 1.8 & 1.1 & 1.2 & 2.6 & 1.5 & IPF9483 \\
\hline CA4204 & 1.9 & 1.9 & 1.0 & 1.3 & 1.8 & 1.5 & HOL4 \\
\hline CA3125* & 6.2 & 2.7 & 2.1 & 1.3 & 3.0 & 2.1 & $F C Y 21.5 f$ \\
\hline CA3249 & 2.5 & 2.2 & 1.6 & 1.4 & 1.6 & 1.6 & GEF2.3f \\
\hline CA2932 & 2.0 & 2.0 & 1.1 & 1.3 & 1.8 & 1.6 & $N H X 1$ \\
\hline CA3545 & 1.8 & 1.5 & 1.2 & 0.8 & 1.5 & 1.8 & BPT1 \\
\hline CA5160 & 1.5 & 1.8 & 1.0 & 1.0 & 1.5 & 1.7 & PHO 89 \\
\hline \multicolumn{8}{|l|}{ Other } \\
\hline CA1010 & 1.6 & 2.0 & 0.9 & 0.7 & 1.7 & 2.7 & GLT1 \\
\hline CA2650 & 2.5 & 3.6 & 1.4 & 1.6 & 1.8 & 2.3 & VPH1 \\
\hline CA2277 & 1.9 & 2.6 & 1.3 & 1.2 & 1.5 & 2.2 & $D R S 21$ \\
\hline CA5890 & 3.9 & 2.1 & 1.1 & 1.2 & 3.5 & 1.7 & FCR1 \\
\hline CA6070 & 2.9 & 2.1 & 1.4 & 1.3 & 2.1 & 1.7 & RHB 1 \\
\hline CA5493 & 3.4 & 1.9 & 1.5 & 1.2 & 2.3 & 1.6 & GCN1.5f \\
\hline CA1288 & 2.8 & 2.3 & 1.3 & 1.5 & 2.1 & 1.5 & $K S P 1$ \\
\hline CA2342 & 2.1 & 2.0 & 1.2 & 1.4 & 1.7 & 1.5 & ASR1 \\
\hline \multicolumn{8}{|c|}{ Un known function } \\
\hline CA5868 & 2.6 & 2.2 & 1.5 & 1.1 & 1.8 & 2.1 & IPF351 \\
\hline CA5246 & 1.8 & 1.8 & 1.2 & 0.9 & 1.5 & 2.0 & IPF19808 \\
\hline CA4951 & 2.2 & 3.1 & 1.5 & 1.6 & 1.5 & 1.9 & IPF13607 \\
\hline CA3173 & 3.5 & 3.0 & 1.9 & 1.6 & 1.9 & 1.9 & PGA47 \\
\hline CA1476 & 2.4 & 2.2 & 0.9 & 1.2 & 2.7 & 1.8 & FLO8 \\
\hline CA5812 & 3.1 & 2.7 & 1.7 & 1.7 & 1.8 & 1.7 & \\
\hline CA6053 & 2.2 & 1.5 & 1.0 & 0.9 & 2.2 & 1.6 & IPF4949 \\
\hline CA2874 & 1.6 & 2.5 & 0.7 & 1.5 & 2.3 & 1.6 & IPF4999 \\
\hline CA3966 & 1.9 & 1.6 & 1.2 & 1.1 & 1.5 & 1.5 & IPF9376 \\
\hline CA1760 & 2.8 & 2.6 & 1.6 & 1.8 & 1.8 & 1.5 & $R B R 3$ \\
\hline CA1433 & 3.4 & 5.1 & 2.0 & 1.6 & 1.7 & 3.2 & IPF12464 \\
\hline CA3565 & 1.7 & 2.1 & 1.0 & 1.2 & 1.8 & 1.8 & MSC2 \\
\hline CA0 110 & 2.2 & 1.9 & 0.8 & 1.1 & 2.8 & 1.7 & IPF17 190 \\
\hline CA4936 & 8.7 & 3.2 & 2.9 & 1.9 & 3.0 & 1.7 & IPF8369 \\
\hline CA2405 & 4.7 & 2.6 & 1.9 & 1.6 & 2.4 & 1.6 & PGA18 \\
\hline
\end{tabular}

\begin{tabular}{|l|l|l|l|l|}
\hline over 1.5 & up to 3 & up to $\mathbf{5}$ & $\begin{array}{l}\text { over } \\
\mathbf{5 . 1}\end{array}$ & Induction / repression \\
\hline over 1.5 & up to 3 & up to $\mathbf{5}$ & $\begin{array}{l}\text { over } \\
\mathbf{5 . 1}\end{array}$ & Wild-type/TW01 ratio \\
\hline
\end{tabular}

Fig. 6 (continued)

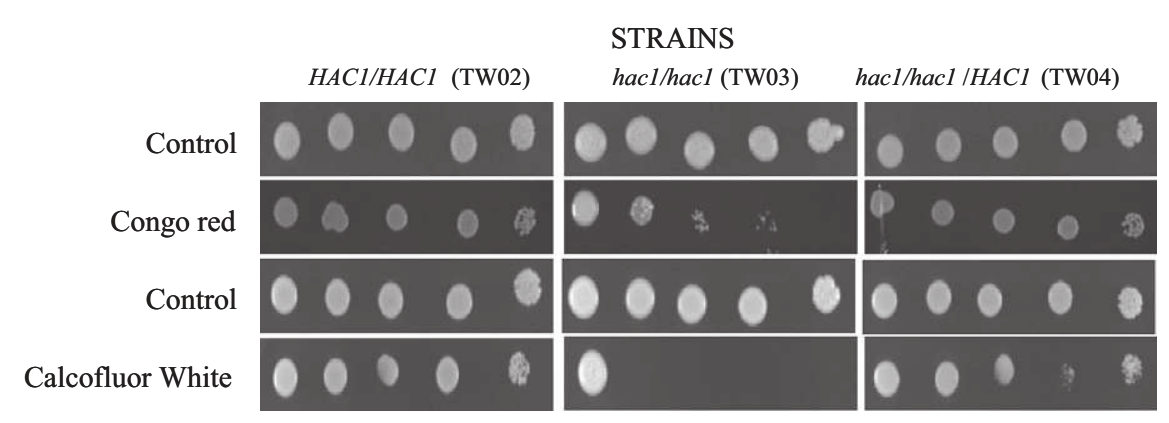

Fig. 7. Sensitivity of the C. albicans WT (TW02), hac1/hac1 (TW03) and hac1/hac1/HAC1 (TW04) strains to cell wall-perturbing agents, Congo red (250 $\mu$ g/ml) and Calcofluor white $30 \mu \mathrm{g} / \mathrm{ml}$. 

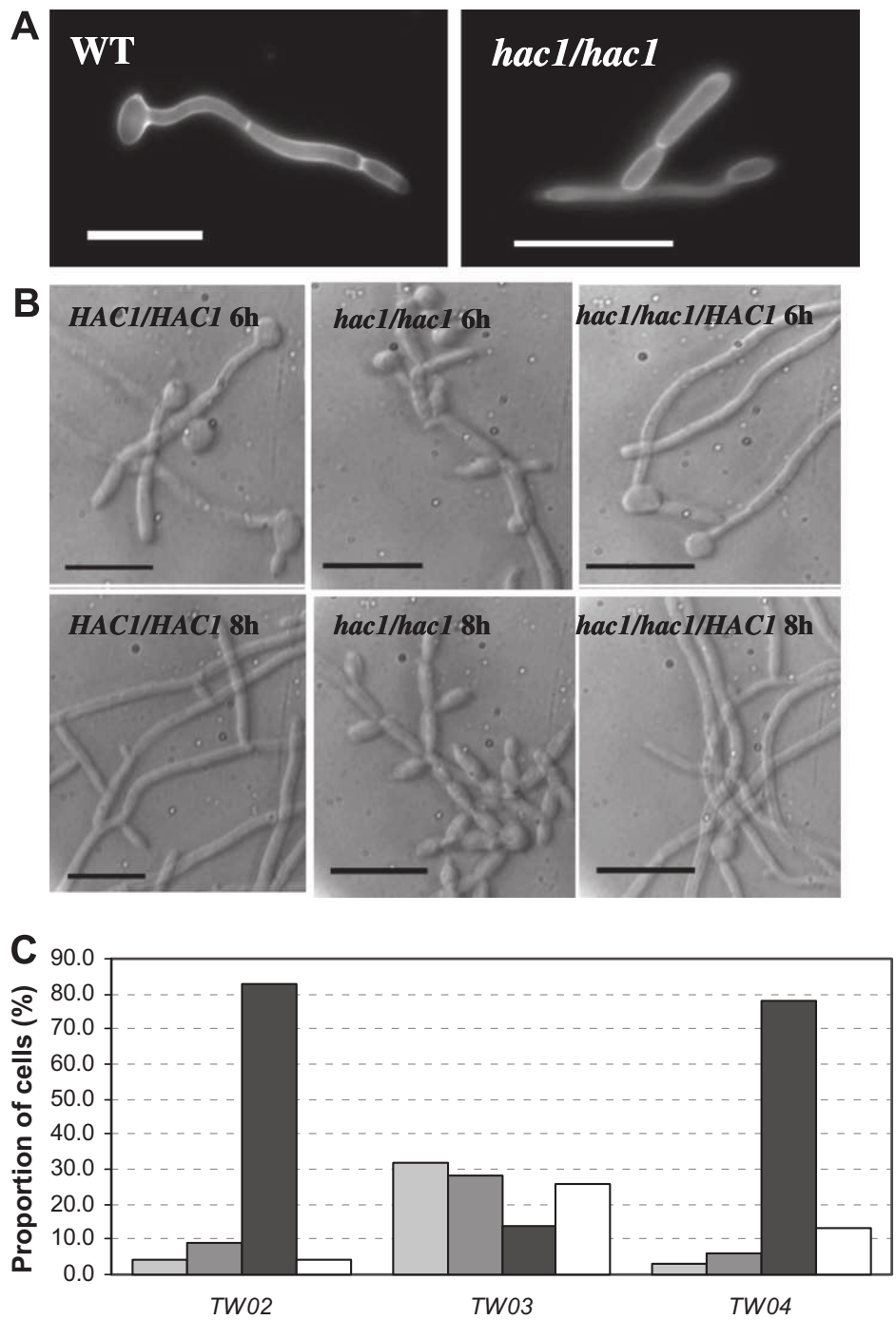

HAC1/HAC1

hac1/hac1

hac1/hac1/HAC1

$\square$ Yeast $\square$ Pseudohyphae $\square$ Hyphae $\square$ Unclassified

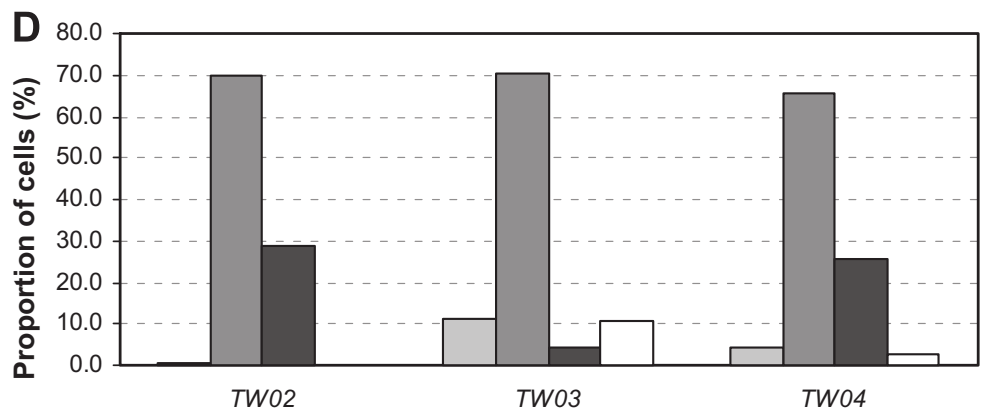

HAC1/HAC1

hac1/hac1

hac1/hac1/HAC1

$\square$ Yeast $\square$ Pseudohyphae $\square$ Hyphae $\square$ Unclassified

Fig. 8. Effect of inactivating Hac1 upon filamentation in C. albicans. (A). WT (BWP17) and hac1/hac1 (TW03) strains grown in YPD containing 20\% (v/v) serum for 5 h, stained with $0.1 \%$ Calcofluor white, and visualized by fluorescence microscopy. Scale bar $=20 \mu \mathrm{m}$. (B) WT, hac1/hac1 and hac1/hac1/HAC1 strains 6 and $8 \mathrm{~h}$ after inoculation in YPD with $20 \%(\mathrm{v} / \mathrm{v})$ serum at $37^{\circ} \mathrm{C}$. Scale bar $=20 \mu \mathrm{m}$. (C) Distribution of the percentage of hyphal-cell forms calculated using Mi in WT, hac1/hac1 and hac1/hac1/HAC1 strains in YPD with $20 \%(\mathrm{v} / \mathrm{v})$ serum at $37^{\circ} \mathrm{C}$ at $6 \mathrm{~h}$ after inoculation (D) Distribution of the percentage of hyphal-cell forms calculated using Mi in WT, hac1/hac1 and hac1/hac1/HAC1 strains in Soll's medium ( $\mathrm{pH} 6.5$ at $37^{\circ} \mathrm{C}$ ) at $5 \mathrm{~h}$ after inoculation. Data represent the average values calculated from each condition for each of duplicate cultures. Cells with Mi from 1.5 to 2.5 were represented as unclassified, because they were not identifiable as yeast, pseudohyphae or hyphae (Brown, 2002). (E) WT, hac1/hac1 and hac1/hac1/ HAC1 cells in YPD with $20 \%(\mathrm{v} / \mathrm{v})$ serum at $37^{\circ} \mathrm{C}, 8 \mathrm{~h}$ after inoculation. Scale bar $=20 \mu \mathrm{m}$. 

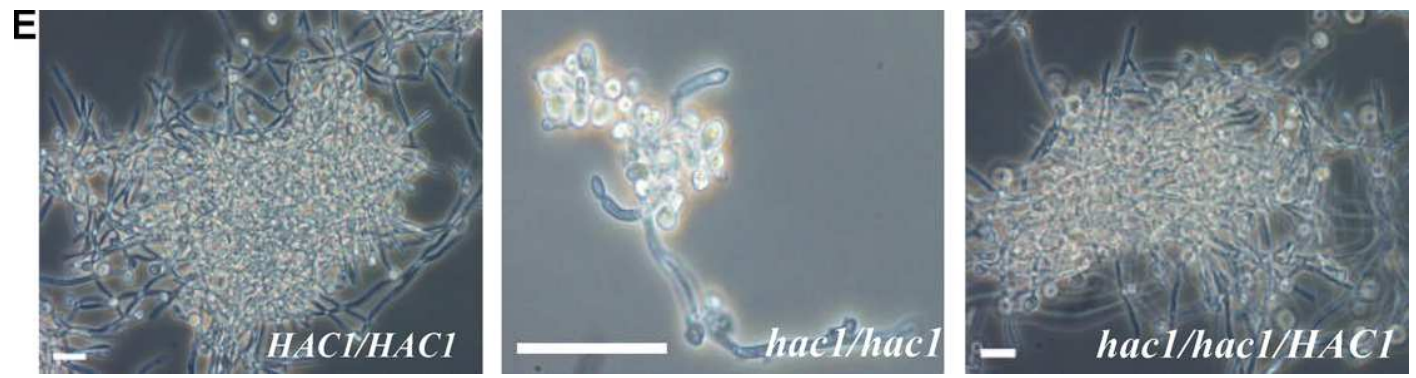

Fig. 8 (continued)

on the regulation of HAC1 orthologues in other fungi (Cox and Walter, 1996; Saloheimo et al., 2003). We also showed that ER stress gives rise to $C$. albicans HAC1 transcripts with truncated $5^{\prime}$ UTRs. This phenomenon is similar to that in filamentous fungi and contrasts with $H A C 1$ regulation in S. cerevisiae. Our complementation studies confirmed that $C$. albicans Hac1 is a functional homologue of $S$. cerevisiae Hac1p, and showed that $S$. cerevisiae is unable to functionally express unspliced versions of the $C$. albicans HAC1 sequence. This reinforces the view that $C$. albicans HAC1 transcripts are processed in a manner that is more similar to filamentous fungi than $S$. cerevisiae.

The microarray studies have defined the genome-wide transcriptional response of $C$. albicans to the ER stresses DTT and tunicamycin (Supplementary Data, Part A). This pathogen responds in a similar manner to S. cerevisiae (Kimata et al., 2005; Travers et al. 2000), namely by up-regulating genes involved in secretion, vesicle trafficking and protein folding, and down-regulating ribosome biogenesis and protein synthesis. Equivalent functions are regulated by the UPR in yeasts and filamentous fungi (Schröder and Kaufman, 2005a; Travers et al., 2000; Kimata et al., 2005; Sims et al., 2005; Guillemette et al., 2007). Hac1 makes a significant contribution to the genome-wide transcriptional response to ER stress in C. albicans. The proportion of genes that was induced ( $\geqslant 1.5$-fold) by both DTT and tunicamycin, and dependent on Hac1, was $20.1 \%$. Affected functions include translocation to and from the ER, vesicle transport, membrane lipid metabolism, protein glycosylation and ER-associated protein degradation (ERAD). IRE1 was not induced by DTT or tunicamycin and neither were any DER genes (involved in ERAD). However, there are some interesting differences between C. albicans and S. cerevisiae. Only 12 genes identified as being Hac1regulated under stress conditions in C. albicans were also found to be Hac1p-regulated under stress in S. cerevisiae. Different criteria were used to identify the UPR genes in $S$. cerevisiae (Travers et al., 2000) so comparisons between the datasets are not straightforward. Although Travers et al. (2000) have provided datasets that catalogue the role of $H A C 1$ in stress responses in S. cerevisiae, there are no equivalent data comparing WT and hac1 cells in the absence of ER stress. We undertook that analysis in C. albicans but, as expected, the results from the array studies did not suggest a dramatic impact on transcription. Under normal growth conditions, the level of $H A C 1^{\mathrm{i}}$ mRNA (leading to the synthesis of Hac1p) is relatively low and the turnover rate of Hac1p is high (Kawahara et al., 1997). It is only under stress conditions that the level of Hac1p is elevated, and where an impact on transcription of target genes that is detectable by arrays, is expected. Even so, the expression of several secretion-related genes was shown to be Hac1-dependent in $C$. albicans and we showed a clear morphological dependence on Hac1 (below).

Given the significant contribution of Hac1 to the genome-wide transcriptional response of $C$. albicans to ER stresses, one might expect the resistance of this organism to such stresses to be compromised following Hac1 inactivation. This was the case, confirming the central role of Hac1 in the $C$. albicans UPR. A previous study has inferred that HAC1 might be an essential gene in C. albicans because it was not possible to generate a homozygous mutant using a split-marker transposon mutagenesis strategy (Nobile and Mitchell, 2005). We demonstrate here that homozygous C. albicans hac1/hac1 null cells are viable, albeit displaying a range of cellular and molecular phenotypes. This is consistent with the situation in other fungi, where HAC1 orthologues are not essential for viability, but do play central roles in the UPR (Cox and Walter, 1996; Saloheimo et al., 2003).

Candida albicans hac1/hac1 cells displayed sensitivities to Calcofluor white and Congo red, which interfere with chitin and glucan synthesis and cross linking, respectively. Sensitivity to Congo red and Calcofluor white is a phenomenon often observed in glycosylation-deficient and cell wall-defective strains (Bates et al., 2005; Ram and Klis, 2006). These phenotypes are consistent with the concept that Hac1 inactivation compromises the integrity of the C. albicans cell wall even if not all aspects of cell wall biogenesis are compromised. Basal ER trafficking and cell wall functions must be retained in hac1/hac1 cells because they are viable. We have shown that Hac1-regulated functions contribute to the polarized growth of $C$. albicans. Hac1 is not essential for hyphal development because some hyphae are formed by $C$. albicans hac1/hac1 cells under the conditions examined (serum, and variation in $\mathrm{pH}$ and temperature). Nevertheless, formation of hyphae is inhibited in hac1/ hac1 cells under these conditions, possibly through inhibition of vesicular trafficking, which is required for polarized growth (Crampin et al., 2005), and the expression of some secretion-related genes was Hac1-dependent under non-stress conditions. The transition from yeast to pseudohyphal cells was shown to be Hac1pdependent in S. cerevisiae (Schröder et al., 2000) but ours is the first demonstration of the importance of Hac1 in a fully filamentous organism and one where virulence is related to hyphal development. hac1 mutant cells display this hyphal defect in the absence of ER stress under conditions where HAC1 mRNA splicing was not detected. It is formally possible that splicing is not required for HAC1 mRNA to mediate its effects upon polarized growth. However, we favour the idea that basal levels of HAC1 mRNA splicing are sufficient to promote polarized growth in the absence of ER stress.

The impact of HAC1 upon hyphal development in C. albicans is significant for several reasons. Firstly, hyphal development contributes to the virulence of this pathogen (Lo et al., 1997; Gow et al., 2002, 2003; Saville et al., 2003; Zheng et al., 2004; Sundström, 2006). Hyphal development in C. albicans is regulated through several signalling pathways including the Ras-cAMP and MAPK pathways (Lo et al., 1997; Ernst, 2000; Brown, 2002). Polarized growth can also be stimulated by amino acid starvation via the bZIP transcription factor, Gcn4 (Tripathi et al., 2002). Hac1p and Gcn4p act in concert to control the expression of some UPR genes in S. cerevisiae (Patil et al., 2004). Therefore C. albicans Hac1 might mediate its effects upon polarized growth independently, or in concert with 
other transcription factors such as Gcn4. Secondly, the yeast-hyphal morphogenetic transition is characterized by alterations in the composition of the $C$. albicans cell wall, which include changes in chitin content and the differential regulation of ALS (agglutininlike sequence) adhesin genes (Munro et al., 1998; Hoyer, 2001; Zhao et al., 2004). The synthesis, delivery and regulation of cell surface molecules are known to contribute to the virulence of $C$. albicans (Staab et al., 1996, 1999; Bates et al., 2005, 2006). The impact of Hac1 in C. albicans is evident from its effect on morphology. The transcriptional dependencies on Hac1 are most evident under ER stress conditions and it is possible that ER stress occurs during invasive growth of $C$. albicans.

\section{Acknowledgments}

T.T.W. was supported by a Full Tuition Fee Scholarship from the University of Nottingham and a partial grant from British Federation of Woman Graduates. B.E. was supported by the European Commission (MRTN-CT-2003-504148), and A.B. by the BBSRC (1/ P17124; BB/C510391/1) and the Wellcome Trust (063204; 08088). We are grateful to Prof. Neil Gow, Dr. Susan Macaskill and Dr. Claire Priest for their help and support, and we thank Lee Shunburne and Trevor Jones for excellent technical assistance.

\section{Appendix A. Supplementary data}

Supplementary data associated with this paper is available to download online at www.ebi.ac.uk/arrayexpress (E-MEXP-1307, Wimalasena 2007). Supplementary data associated with this article can be found, in the online version, at doi:10.1016/ j.fgb.2008.06.001.

\section{References}

Bates, S., Hughes, H.B., Munro, C.A., Thomas, W.P.H., MacCallum, D.M., Bertram, G. Atrih, A., et al., 2006. Outer chain $\mathrm{N}$-glycans are required for cell wall integrity and virulence of Candida albicans. J. Biol. Chem. 28, 90-98.

Bates, S., MacCallum, D.M., Bertram, G., Munro, C.A., Hughes, H.B., Burman, E.T Brown, A.J.P., et al., 2005. Candida albicans Pmr1p, a secretory pathway P-type $\mathrm{Ca}^{2+} / \mathrm{Mn}^{2+}$-ATPase, is required for glycosylation and virulence. J. Biol. Chem. 280 $23408-23415$

Brand, A., MacCallum, D.M., Brown, A.J., Gow, N.A., Odds, F.C., 2004. Ectopic expression of URA3 can influence the virulence phenotypes and proteome of Candida albicans but can be overcome by targeted reintegration of URA3 at the RPS10 locus. Eukaryot. Cell 3, 900-909.

Brown, A.J.P., 2002. Expression of growth form-specific factors during morphogenesis in Candida albicans. In: Calderone, R. (Ed.), Candida and Candidiasis. ASM Press, pp. 87-93.

Brown, A.J.P., Argimón, S., Gow, N.A.R., 2007. Signal transduction and morphogenesis in Candida albicans, second ed.. In: Howard, R.J., Gow, N.A.R (Eds.), The Mycota VIII, vol. 8 Springer-Verlag, Heidelberg, pp. 165-192.

Buffo, J., Herman, M.A., Soll, D.R., 1984. A characterization of pH-regulated dimorphism in Candida albicans. Mycopathologia 85, 21-30.

Calderone, R.A., 2002. Taxonomy and biology of Candida. In: Calderone, R. (Ed.), Candida and Candidiasis. ASM Press, pp. 15-27.

Calfon, M., Zeng, H., Urano, F., Till, J.H., Hubbard, S.R., Harding, H.P., Clark, S.G., Ron, D., 2002. IRE1 couples endoplasmic reticulum load to secretory capacity by processing the XBP1 mRNA. Nature 415, 92-96.

Chaffin, W.L., 1985. Effect of tunicamycin on germ tube and yeast bud formation in Candida albicans. J. Gen. Microbiol. 131, 1853-1861.

Court, H., Sudbery, P., 2007. Regulation of Cdc42 GTPase activity in the formation of hyphae in Candida albicans. Mol. Biol. Cell 18, 265-281.

Cox, J.S., Walter, P., 1996. A novel mechanism for regulating activity of a transcription factor that controls the unfolded protein response. Cell 87, 391 404.

Crampin, H., Finley, K., Gerami-Nejad, M., Court, H., Gale, C., Berman, J., Sudbery, P. 2005. Candida albicans hyphae have a Spitzenkörper that is distinct from the polarisome found in yeast and pseudohyphae. J. Cell Sci. 118, 2935-2947.

Dennison, P.M.J., Ramsdale, M., Manson, C.L., Brown, A.J.P., 2005. Gene disruption in Candida albicans using a synthetic, codon-optimised Cre-loxP system. Fungal Genet. Biol. 42, 737-748.

Enjalbert, B., Smith, D.A., Cornell, M., Alam, I., Nicholls, S., Brown, A.J.P., Quinn, J., 2006. Role of Hog1 stress-activated kinase in the global transcriptional response to stress in the fungal pathogen Candida albicans. Mol. Biol. Cell 17 1018-1032.
Enjalbert, B., Whiteway, M., 2005. Release from quorum-sensing molecules triggers hyphal formation during Candida albicans resumption of growth. Eukaryot. Cell 4, 1203-1210.

Ernst, J.F., 2000. Regulation of dimorphism in Candida albicans. In: Ernst, J.F., Schmidt, A. (Eds.), Dimorphism in Human Pathogenic and Apathogenic Yeasts. Karger, Basel, pp. 98-111.

Gietz, R.D., Woods, R.A., 2002. Transformation of yeast by lithium acetate/singlestranded carrier DNA/polyethylene glycol method. Methods Enzymol. 350, 8796.

Gillum, A.M., Tsay, E.Y., Kirsch, D.R., 1984. Isolation of the Candida albicans gene for orotidine- $5^{\prime}$-phosphate decarboxylase by complementation of $S$. cerevisiae ura 3 and E. coli pyrF mutations. Mol. Gen. Genet. 198, 179-182.

Gow, N.A.R., Brown, A.J.B., Odds, F.C., 2002. Fungal morphogenesis and host invasion. Curr. Opin. Microbiol. 5, 366-371.

Gow, N.A.R., Knox, Y., Munro, C.A., Thompson, W.D., 2003. Infection of chick chorioallantoic membrane (CAM) as a model for invasive hyphal growth and pathogenesis of Candida albicans. Med. Mycol. 41, 331-338.

Guillemette, T., van Peij, N.N.M.E., Goosen, T., Lanthaler, K., Robson, G.D., van den Hondel, C.A.M.J.J., Archer, D.B., 2007. Genomic analysis of the secretion stress response in the enzyme-producing cell factory Aspergillus niger. BMC Genomics $8,158$.

Hauser, N.C., Vingron, M., Scheideler, M., Krems, B., Hellmuth, K., Entian, K.D. Hoheisel, J.D., 1998. Transcriptional profiling on all open reading frames of Saccharomyces cerevisiae. Yeast 14, 1209-1221.

Hoyer, L.L., 2001. The ALS gene family of Candida albicans. Trends Microbiol. 9, 176180.

Hudson, D.A., Sciascia, Q.L., Sanders, R.J., Norris, G.E., Edwards, P.J.B., Sullivan, P.A., Farley, P.C., 2004. Identification of the dialysable serum inducer of germ-tube formation in Candida albicans. Microbiology 150, 3041-3049.

Kaufman, R. Scheuner, D., Schroder, M., Shen, X., Lee, K., Liu, C.Y., Arnold, S.M. 2002. The unfolded protein response in nutrient sensing and differentiation. Nat. Rev. Mol. Cell Biol. 3, 411-421.

Kawahara, T., Yanagi, H., Yura, T., Mori, K., 1997. Endoplasmic reticulum stressinduced mRNA splicing permits synthesis of transcription factor Hac1p/Ern4p that activates the unfolded protein response. Mol. Biol. Cell 8, 1845-1862.

Kimata, Y., Ishiwata-Kimata, Y., Yamada, S., Kohno, K., 2005. Yeast unfolded protein response pathway regulates expression of genes for anti-oxidative stress and for cell surface proteins. Genes Cells 11, 59-69.

Klengel, T., Liang, W., Chaloupka, J., Ruoff, C., Schroppel, K., Naglik, J.R., Eckert, S.E., et al., 2005. Fungal adenylyl cyclase integrates C02 sensing with cAMP signalling and virulence. Curr. Biol. 15, 2021-2026.

Lay, J., Henry, L.K., Clifford, J., Koltin, Y., Bulawa, C.E., Becker, J.M., 1998. Altered expression of selectable marker URA3 in gene-disrupted Candida albicans strains complicates interpretation of virulence studies. Infect. Immun. 66, 5301-5306.

Leber, J.H., Bernales, S., Walter, P., 2004. IRE1-independent gain control of the unfolded protein response. PLoS Biol. 2, 1197-1207.

Lo, H.J., Köhler, J.R., DiDomenico, B., Loebenberg, D., Cacciapuoti, A., Fink, G.R., 1997. Nonfilamentous C. albicans mutants are avirulent. Cell 90, 939-949.

Maidan, M.M., Thevelein, J.M., van Dijck, P., 2005. Carbon source induced yeast-tohypha transition in Candida albicans is dependent on the presence of amino acids and on the G-protein-coupled receptor Gpr1. Biochem. Soc. Trans. 33, 291-293.

Martchenko, M., Levitin, A., Whiteway, M., 2007. Transcriptional activation domains of the Candida albicans Gcn4p and Gal4p homologs. Eukaryot. Cell 6, 291-301.

Melcher, K., 2000. A modular set of prokaryotic and eukaryotic expression vectors. Anal. Biochem. 277, 109-120.

Merson-Davis, L.A., Odds, F.C., 1989. A morphology index for characterization of cell shape in Candida albicans. J. Gen. Microbiol. 135, 3143-3152.

Mori, K., Kawahara, T., Yoshida, H., Yanagi, H., Yura, T., 1996. Signalling from endoplasmic reticulum to nucleus: transcription factor with a basic-leucine zipper motif is required for the unfolded protein-response pathway. Genes Cells $1,803-817$.

Mulder, H.J., Saloheimo, M., Penttilä, M., Madrid, S.M., 2004. The transcription factor HACA mediates the unfolded protein response in Aspergillus niger, and upregulates its own transcription. Mol. Gen. Genom. 271, 130-140.

Munro, C.A., Schofield, D.A., Gooday, G.W., Gow, N.A.R., 1998. Regulation of chitin synthesis during dimorphic growth of Candida albicans. Microbiology 144, 391 401.

Murad, A.M.A., Lee, P.R., Broadbent, I.D., Barelle, C.J., Brown, A.J.B., 2000. CIp10, an efficient and convenient integrating vector for Candida albicans. Yeast 16, 325327.

Nobile, C.J., Mitchell, A.P., 2005. Regulation of cell-surface genes and biofilm formation by the C. albicans transcription factor Bcr1p. Curr. Biol. 15, 11501155.

Odds, F.C., 1988. Candida and Candidiasis, second ed. Bailliere Tindall, London.

Patil, C.K., Li, H., Walter, P., 2004. Gcn4p and novel upstream activating sequences regulate targets of the unfolded protein response. PLoS Biol. 2, 1208-1223.

Ram, A.F., Klis, F.M., 2006. Identification of fungal cell wall mutants using susceptibility assays based on Calcofluor white and Congo red. Nat. Protocols $1,2253-2256$

Rüegsegger, U., Leber, J.H., Walter, P., 2001. Block of HAC1 mRNA translation by long-range base pairing is released by cytoplasmic splicing upon induction of the unfolded protein response. Cell 107, 103-114.

Saloheimo, M., Valkonen, M., Penttilä, M., 2003. Activation mechanisms of the HAC1mediated unfolded protein response in filamentous fungi. Mol. Microbiol. 47, 1149-1161. 
Sambrook, J., Fritsch, E.F., Maniatis, T., 1989. Molecular Cloning: A Laboratory Manual, second ed. Cold Spring Harbor Laboratory Press, New York.

Saville, S.P., Lazzell, A.L., Monteagudo, C., Lopez-Ribot, J.L., 2003. Engineered control of cell morphology in vivo reveals distinct roles for yeast and filamentous forms of Candida albicans during infection. Eukaryot. Cell 2, 1053-1060.

Schröder, M., Kaufman, R.J., 2005a. ER stress and the unfolded protein response. Mutat. Res. 569, 29-63.

Schröder, M., Kaufman, R.J., 2005b. The mammalian unfolded protein response. Annu. Rev. Biochem. 74, 739-789.

Schröder, M., Chang, J.S., Kaufman, R.J., 2000. The unfolded protein response represses nitrogen-starvation induced developmental differentiation in yeast. Genes. Dev. 14, 2962-2975.

Schröder, M., Clark, R., Kaufman, R.J., 2003. IRE1- and HAC1-independent transcriptional regulation in the unfolded protein response of yeast. Mol. Microbiol. 49, 591-606.

Sherman, F., 1991. Getting started with yeast. Methods Enzymol. 194, 3-21.

Sims, A.H., Gent, M.E., Lanthaler, K., Dunn-Coleman, N.S., Oliver, S.G., Robson, G.D., 2005. Transcriptome analysis of recombinant protein secretion by Aspergillus nidulans and the unfolded-protein response in vivo. Appl. Environ. Microbiol. 71, 2737-2747.

Staab, J.F., Bradway, S.D., Fidel, P.L., Sundström, P., 1999. Adhesive and mammalian transglutaminase substrate properties of Candida albicans Hwp1. Science 283, 1535-1539.

Staab, J.F., Ferrer, C.A., Sundström, P., 1996. Developmental expression of a tandemly repeated, proline- and glutamine-rich amino acid motif on hyphal surfaces of Candida albicans. J. Biol. Chem. 271, 6298-6305.

Stoldt, V.R., Sonneborn, A., Leuker, C.E., Ernst, J., 1997. Efg1p, an essential regulator of morphogenesis of the human pathogen Candida albicans, is a member of a conserved class of bHLH proteins regulating morphogenetic processes in fungi. EMBO J. 16, 1982-1991.

Sudbery, P.E., 2001. The germ tubes of Candida albicans hyphae and pseudohyphae show different patterns of septin ring localization. Mol. Microbiol. 41, 19-31.

Sudbery, P., Gow, N., Berman, J., 2004. The distinct morphogenic states of Candida albicans. Trends Microbiol. 12, 317-324.

Sundström, P., 2006. Candida albicans hypha formation and virulence. In: Heitman, J., Filler, S.G., Edwards, J.E., Mitchell, A.P. (Eds.), Molecular Principles of Fungal Pathogenesis. ASM Press, Washington, DC, pp. 45-47.

Sundström, P., Cutler, J.E., Staab, J.F., 2002. Reevaluation of the role of HWP1 in systemic candidiasis by use of Candida albicans strains with selectable marker URA3 targeted to the ENO1 locus. Infect. Immun. 70, 3281-3283.
Swoboda, R.K., Bertram, G., Delbruck, S., Ernst, J.F., Gow, N.A.R., Gooday, G.W., Brown, A.JP. 1994. Fluctuations in glycolytic mRNA levels during the yeast-tohyphal transition in Candida albicans reflect underlying changes in growth rather than a response to cellular dimorphism. Mol. Microbiol. 13, 663-672.

Timpel, C., Strahl-Bolsinger, S., Ziegelbauer, K., Ernst, J.F., 1998. Multiple functions of Pmt1p-mediated protein O-mannosylation in the fungal pathogen Candida albicans. J. Biol. Chem. 273, 20837-20846.

Timpel, C., Zink, S., Strahl-Bolsinger, S., Schröppel, K., Ernst, J.F., 2000. Morphogenesis, adhesive properties, and antifungal resistance depend on the Pmt6 protein annosyltransferase in the fungal pathogen Candida albicans. J. Bacteriol. 182, 3063-3071.

Tournu, H., Tripathi, G., Bertram, G., Macaskill, S., Mavor, A., Walker, L., Odds, F.C., et al., 2005. Global role of the protein kinase Gcn2 in the human pathogen Candida albicans. Eukaryot. Cell 4, 1687-1696.

Travers, K.J., Patil, C.K., Wodicka, L., Lockhart, D.J., Weissman, J.S., Walter, P., 2000. Functional and genomic analyses reveal an essential coordination between the unfolded protein response and ER-associated degradation. Cell 101, 249-258.

Tripathi, G., Wiltshire, C., Macaskill, S., Tournu, H., Budge, S., Brown, A.J.P., 2002. Gcn4 co-ordinates morphogenetic and metabolic responses to amino acid starvation in Candida albicans. EMBO J. 21, 5448-5456.

Tusher, V.G., Tibshirani, R., Chu, G., 2001. Significance analysis of microarrays applied to the ionizing radiation response. Proc. Natl. Acad. Sci. USA 98, 51165121.

Verstrepen, K.J., Klis, F.M., 2006. Flocculation, adhesion and biofilm formation in yeasts. Mol. Microbiol. 60, 5-15.

Verstrepen, K.J., Reynolds, T.B., Fink, G.R., 2004. Origins of variation in the fungal cell surface. Nat. Rev. Microbiol. 2, 1-9.

Whiteway, M., Oberholzer, U., 2004. Candida morphogenesis and host-pathogen interactions. Curr. Opin. Microbiol. 7, 350-357.

Wilson, R.B., Davis, D., Mitchell, A.P., 1999. Rapid hypothesis testing with Candida albicans through gene disruption with short homology regions. J. Bacteriol. 181, 1868-1874.

Zhao, X., Oh, S.H., Cheng, G., Green, C.B., Nuessen, J.A., Yeater, K., Leng, R.P., et al., 2004. ALS3 and ALS8 represent a single locus that encodes a Candida albicans adhesion; functional comparisons between Als3p and Als1p. Microbiology 150, $2415-2428$.

Zheng, X., Wang, Y., Wang, Y., 2004. Hgc1, a novel hypha-specific G1 cyclin-related protein regulates Candida albicans hyphal morphogenesis. EMBO J. 23, 18451856. 